\title{
Deletion of Small Ubiquitin-like Modifier-1 Attenuates Behavioral and Anatomical Deficits by Enhancing Functional Autophagic Activities in Huntington Disease
}

Uri Nimrod Ramírez-Jarquín ${ }^{1}$, Manish Sharma ${ }^{1}$, Neelam Shahani¹, and Srinivasa Subramaniam*1

Department of Neuroscience, The Scripps Research Institute, Jupiter, Florida 33458, USA *Co-correspondence, Tel: 561-228-2104; Fax: 561-228-2107; E-mail:

nshahani@scripps.edu; ssubrama@scripps.edu

\section{ABSTRACT}

Mutant HTT (mHTT) associated with Huntington disease (HD) affects the central nervous system by prominent atrophy in the striatum and promotes psychiatric, cognitive, and choreiform movements, although the exact mechanism remains obscure. Previous studies have shown that SUMO1 (Small Ubiquitin-like Modifier-1) modification of MHTT promotes cellular toxicity, but the in vivo role and functions of SUMO1 in HD pathogenesis are unclear. Here, we report that SUMO1 deletion in Q175DN HD-het knock-in mice (HD mice) prevented age-dependent HD-like motor and neurological impairments and suppressed the striatal atrophy and inflammatory response. SUMO1 deletion caused a drastic reduction in soluble $\mathrm{mHtt}$ levels and nuclear and extracellular $\mathrm{mHtt}$ inclusions, while increasing cytoplasmic inclusions in the striatum of HD mice. SUMO1 deletion also enhanced autophagic activity, characterized by augmented interactions between $\mathrm{mHTT}$ inclusions and a lysosomal marker (LAMP1), increased LC3B/LAMP1 interaction, and decreased sequestosome-1 (p62) and $\mathrm{mHTT}$ and diminished p62/LAMP1 interactions in DARPP-32-positive medium spiny neurons (MSNs) in HD mice. Depletion of SUMO1 in an $\mathrm{HD}$ cell model also diminished the $\mathrm{mHtt}$ levels and enhanced autophagy flux. In addition, the SUMOylation inhibitor ginkgolic acid strongly enhanced autophagy and diminished mHTT levels in human HD fibroblasts. These results indicate that SUMO is a critical therapeutic target in $\mathrm{HD}$ and that blocking SUMO may ameliorate HD pathogenesis by improving autophagy activities. 


\section{KEY WORDS}

Post-translational modification, gene expression, IPA pathway, inflammatory signaling, ubiquitin, protein-complex, striatal vulnerability, brain, motor abnormality

\section{INTRODUCTION}

Expansion of the CAG repeat in the huntingtin (HTT) gene causes the motor disturbance, cognitive loss, and psychiatric manifestations associated with Huntington Disease (HD). This mutant HTT (mHTT) affects multiple signaling and pathways, including vesicle- and microtubule-associated protein/organelle transport, transcription, and calcium, sphingosine, cysteine, and p53/GAPDH signaling, as well as functional connectivity, secretory pathway function, cell division, mitochondrial abnormalities, and ribosome stalling [1-23]. However, the exact mechanism by which mHTT induces its pathological effects in the brain remains unclear.

Multiple lines of evidence point to an aberration in autophagy-an essential degradative pathway that maintains neuronal homeostasis-as the root cause of HD [2428]. Studies have implicated aberrant autophagy in $\mathrm{HD}[27,28]$, as well as a failure of autophagic processes such as cargo-loading, in the accumulation of $\mathrm{mHTT}$ and the progression of the disease $[24,25,29]$. Normal HTT serves as an autophagy scaffold and interacts with the Atg8 homologs, ULK1 and p62, during autophagy [30, 31] but the molecular mechanism and the precise role of $\mathrm{mHTT}$ in autophagy dysregulation remain elusive [32]. Accordingly, molecular and pharmacological agents that can promote mTOR-dependent and independent-mechanisms of autophagy are being actively tested in preclinical models [33-55]. Nevertheless, the actual alterations in autophagy homeostasis and the treatments that can lead to its restoration are unknown [32, 56]. This gap in knowledge remains a major hurdle in identifying targets for successful treatment of HD.

One potential target is the small-ubiquitin-like modifier (SUMO), which consists of three ubiquitously expressed paralogs in vertebrates: SUMO1, SUMO2, and SUMO3. It is a conserved $\sim 10.5 \mathrm{kDa}$ protein modifier that attaches covalently to lysine residues on multiple substrate proteins in a dynamic and reversible manner [57] in a process known as SUMOylation. Protein modification by SUMO is implicated in a diverse array of 
neurological disorders [58-62] and is known to regulate a wide range of cellular processes, including gene expression, nuclear transport, signal transduction, apoptosis, and autophagy [63-77]. Experiments with null mice confirm that SUMO1 and SUMO3 are indispensable for development, while deletion of SUMO2 is embryonically lethal[78-80]. These studies indicate critical roles for SUMO in an organism's growth and development, but its mechanistic connection to neurodegenerative disease is less clear.

We have reported that a striatal enriched protein, Rhes, is SUMO modified on multiple lysine residues and serves as a physiological regulator of SUMOylation and gene transcription $[81,82]$. Rhes interacts with mHTT and modifies it by SUMO1, consistent with other reports [83, 84]. SUMO1 modification of mHTT increases the solubility of mHTT, enhances Rhes-mediated transport of vesicle-bound $\mathrm{mHTT}$ via tunneling-like nanotubes [85], and promotes cellular toxicity [86]. Accordingly, Rhes deletion ameliorates, and Rhes overexpression worsens, the HD phenotype in HD cell models (primary neurons, mouse cells, and hESC-derived medium spiny neurons [MSNs]) and HD mouse models [86-94]. Recently, Rhes has been linked to tau-mediated pathology involving SUMOylation, and Rhes alterations are now identified as a novel hallmark of tauopathies $[95,96]$. These studies indicate that Rhes-SUMO signaling pathways participate in neurodegenerative disease processes by regulating disease-relevant proteins.

However, no mechanisms or systematic evaluations have been identified to explain how SUMO might determine the course of neuronal decline and eventual striatal atrophy in slowly progressing knock-in HD mouse models. Here, we deleted SUMO1 in the Q175DN HD-het (Q175DN) knock-in mouse model of HD [97], which contains the human HTT exon 1 with expanded CAG repeats, and we characterized the resulting Q175DN-SUMO1KO mouse line longitudinally to determine the role of SUMO1 in terms of the nature, extent, and age of onset of behavioral deficits. We also performed anatomical, molecular, and biochemical signaling of the striatal tissues. Finally, we evaluated the effect of SUMO1 deletion or pharmacological SUMO inhibition on biochemical signaling by using HD mouse and human cell culture models.

\section{RESULTS}




\section{SUM01 deletion diminishes HD-associated behavioral deficits in Q175DN mice.}

To determine the role of SUMO1 in HD pathogenesis using HD knock-in mice [neomycindeleted Q175DN HD-het (Q175DN)] mice [97], we generated HD mice lacking a SUMO1 gene (Q175DN-SUMO1KO). We included mice of both genders at a mixed ratio in our longitudinal analysis (Fig. 1A, Table 1). A slight decrease in body weight was noted at about 10 months of age in the Q175DN mice $(n=28)$, consistent with previous reports[9799], also in the Q175DN-SUMO1KO mice ( $n=30$ ) when compared to the control groups (WT, $\mathrm{n}=37$ and SUMO1KO, $\mathrm{n}=27$ ), indicating that SUMO1 does not modulate the body weight loss observed in HD (Fig. 1B). However, the Q175DN-SUMO1KO mice did not show the progressively worsening rotarod behavior deficits that were observed in the Q175DN mice beginning at 8-10 months of age [97] (Fig. 1C). The Q175DN mice also showed deficits in fine motor coordination and balance in beam walking, but these deficits were also diminished in the Q175DN-SUMO1KO mice (Fig. 1D). Open-field tests revealed age-dependent hypoactivity in the Q175DN mice compared to WT mice, whereas the Q175DN-SUMO1KO mice showed significantly less hypoactivity compared to Q175DN at 8 months but not in later months (Fig. 1E). We also employed a battery of behavioral tests to quantify the neurological dysfunction. These tests include walking on a ledge, clasping, gait, kyphosis (spine curvature), and tremor, which can be averaged as a 'composite' score [100]. Behavioral battery tests revealed that Q175DN mice performed worst on ledge, clasping, gait, kyphosis, and tremor testing, but the performance of these tasks was significantly better in Q175DN-SUMO1KO mice in both individual tests and composite scores (Fig. 1F, G). Thus, SUMO1 deletion attenuated the severity of behavioral and neurological abnormalities associated with HD.

\section{SUMO1 deletion abolishes striatal atrophy in HD mice.}

We also analyzed whether the behavioral protection induced by SUMO1 deletion is accompanied by changes in anatomical deficits. We sacrificed the mice after the behavioral analysis at approximately 13 months of age and examined striatal anatomical alterations by measuring the lateral ventricular area (an indirect measurement of striatal atrophy). We observed lateral ventricle enlargement in the Q175DN mice in the frontal, central, and caudal regions of the striatum, consistent with previous reports [97, 99] (Fig. 
2A and B). This enlargement was markedly diminished in the Q175DN-SUMO1KO mice in all three striatal regions, and the lateral ventricle sizes were comparable to those of the WT and SUMO1KO control groups (Fig. 2A and B). Thus, SUMO1 deletion almost completely prevented the striatal atrophy observed in the knock-in HD mice.

\section{Effect of SUMO1 deletion on the striatal gene expression landscape in HD mice.}

Transcriptional dysregulation is a major event in HD pathogenesis [6, 7, 13, 101-103], and SUMO is involved in the transcriptional repression as well as activation functions [104-106]. We therefore examined whether SUMO1 impacts striatal atrophy in HD (Fig. $2 \mathrm{~A}, \mathrm{~B})$ by a dysregulation of gene expression. We performed a genome wide striatal tissue-specific gene expression pattern analysis by comparing RNA seq in the striatum of 13-month-old WT, Q175DN, Q175DN-SUMO1KO, and SUMO1KO mice ( $\mathrm{n}=3 /$ group). Gene counts revealed 1042 genes that were significantly upregulated and downregulated (padj < 0.05) in the Q175DN compared to the WT striatum (Data file 1). Ingenuity pathway network analysis (IPA) revealed significant alterations in canonical pathways, such as cAMP-response element binding protein (CREB), opioid signaling, endocannabinoid signaling, G-protein-coupled receptors (GPCR), and glutamate receptor signaling, as well as fragile X mental retardation 1 (FMR1) signaling, between the WT and Q175DN striatum (Fig. 2C, D, Data file 1). Some of these altered pathways in Q175HD have been previously reported[107]. We found significant alterations of 255 genes between WT and SUMO1KO mice (padj < 0.05) and of 2308 genes between SUMO1KO and Q175DN mice (padj < 0.05); most of the altered genes involved opioid signaling, CREB signaling, and GPCR signaling, among others (Data file 1, Supp Fig. 1). However, we found very few differentially expressed genes between Q175DN-SUMO1KO and Q175DN mice striatum (padj < 0.05). Of the 18 genes discovered, 5 were downregulated and 13 were upregulated (Fig. 2E). Due to the small number of gene alterations, IPA analysis did not identify a comprehensive network of biological processes or pathways, as the number of connectible entities with sufficiently high z-scores was insufficient. However, IPA did hint that the modulated genes belonged to hypoxia, circadian rhythm, DNA methylation, and inflammatory processes (Fig. 2F) in Q175DN-SUMO1KO compared to Q175DN mice striatum. These results indicate that SUMO1 has only a nominal impact on the overall 
gene expression changes occurring in the HD striatum, suggesting that SUMO1 may promote striatal atrophy via post-transcriptional and/or post-translational mechanisms.

\section{SUMO1 deletion prevents the inflammatory responses of HD.}

Since the IPA analysis suggested that the linked altered genes were functionally enriched in inflammatory responses in Q175DN-SUMO1KO compared to Q175DN mice striatum (Fig. 2F), we carried out glial fibrillary acidic protein (GFAP) immunoreactivity assays to assess the inflammatory changes within the frontal, central, and caudal regions of striatal sections from the WT, Q175DN, Q175DN-SUMO1KO, and SUMO1KO mice (Fig. 3A). GFAP expression was strikingly enhanced in all regions, with a slightly increased signal in the central striatum, in Q175DN mice compared to WT mice (Fig. 3A, B), consistent with previous reports [108, 109]. The Q175DN-SUMO1KO mice showed a marked decrease in GFAP immunoreactivity in all three regions compared to the Q175DN mice (inset $\mathrm{c}$ and $\mathrm{e}$ ), whereas GFAP immunoreactivity was unaltered between the WT and SUMO1KO striatum (Fig. 3A, B). Higher GFAP expression is also seen in the cortical region of Q175DN mice (inset d) which is also diminished in the Q175DN-SUMO1KO (inset f).

Western blot analysis of the striatal tissue further confirmed that GFAP protein expression, but not mRNA expression, was significantly reduced in the Q175DNSUMO1KO mice compared to the Q175DN mice (Fig. 3C, D, E). The protein levels of DARPP-32, a commonly used biochemical MSN marker for striatal damage in HD [110, 111], was diminished in Q175DN mice compared to WT mice. This reduction is likely due to diminished DARPP-32 mRNA in Q175DN mice (Fig. 3E). The Q175DN-SUMO1KO mice showed a similar extent of loss of DARRP-32 protein and mRNA, indicating SUMO1 may not interfere with the transcriptional downregulation of DARPP-32 in the HD striatum (Fig. 3E). These results indicate that SUMO1 deletion prevents the striatal atrophy that is accompanied by a strong reduction in the inflammatory glial response in the striatum.

\section{SUMO1 deletion enhances EM48+ aggregates and decreases soluble forms of HTT.}

As SUMO plays a major role in regulating protein aggregation, including aggregation of mHTT [60, 84, 86, 112-115], we also analyzed the aggregated and soluble forms of mHTT by immunohistochemistry (IHC) and western blotting. We used EM48 antibody, the most 
sensitive antibody for detecting mHTT inclusions [116, 117], as well as MAB2166 (clone 1HU-4C8) [117, 118] and polyQ (clone 3B5H10) [119, 120] antibodies to detect FL-HTT. Immunofluorescent staining of striatal brain sections of WT or SUMO1KO mice with EM48 antibody did not reveal any inclusions (data not shown), so these mice were not included in further analysis. However, EM48 antibody readily detected HTT aggregates in Q175DN and Q175DN-SUMO1KO striatal brain sections in both the cortex and striatum (Fig. 4A), consistent with previous report [97]. The numbers of DARPP-32+ neurons between Q175DN and Q175DN-SUMO1KO mice did not differ (Fig. 4A, B); however, a stronger colocalization of EM48+ punctae was observed in DARPP-32 MSNs (Fig. 4C, D) in the striatum of Q175DN-SUMO1KO mice than in Q175DN mice. These data indicated that SUMO1 deletion altered the MHTT distribution in MSNs. Therefore, we further analyzed the distribution of EM48+ aggregates in the cell soma, nucleus, and extracellular space.

Confocal analysis revealed no differences in the numbers of cells (DAPI+) or total EM48+ mHTT aggregates between Q175DN and Q175DN-SUMO1KO mice (Fig. 4E, F, G). However, the number of nuclear EM48+ aggregates (solid arrowhead, Fig. 4E, H) in the DARPP-32+ neurons and extracellular EM48+ aggregates (asterisk) was significantly diminished (Fig. 4E, I), whereas the cytoplasmic EM48+ aggregates (open arrowhead) in DARPP-32+ neurons were increased in the Q175DN-SUM01KO mice compared to the Q175DN mice (Fig. 4E, J).

Western blotting analysis of striatal brain lysates prepared in non-denaturing Tris buffer (which enriches cytoplasmic proteins [121, 122]) showed a significant enhancement of EM48+ aggregates in the Q175DN-SUMO1KO striatum, compared to the Q175DN striatum (Fig. 4K, L), supporting confocal findings that SUMO1 deletion increased the cytoplasmic EM48+ mHTT levels. As expected no EM48+ aggregates were seen in WT and SUMO1KO control groups (Fig. 4K). We then probed the same lysates for MAB2166 antibody (which detects both HTT and mHTT) or polyQ antibody to detect full length (FL)-mHTT and mHTT. We found diminished levels of HTT levels as well as poly Q mHTT in the Q175DN mice striatum, consistent with earlier reports [123, 124], but a further diminishment in the Q175DN-SUMO1KO striatum (Fig. 4K, M). Note, normal HTT protein levels are also diminished in SUMO1KO striatum (Fig. 4K, M). Next we determined if SUMO1 regulates the HTT mRNA. We found that while HTT mRNA is 
significantly diminished in the Q175DN mice compared to WT, it remained diminished to a similar extent in the Q175DN-SUMO1KO mice. The mRNA of normal HTT is similar between WT and SUMO1KO striatum (Fig. 4K, O). Thus, SUMO1 deletion reduces the protein levels of mHTT as well as normal HTT, but not their mRNA levels, in the striatum, indicating post-transcriptional and/or post-translational mechanisms.

\section{SUM01 deletion enhances the p62 and EM48+ interaction and autophagic activities in the striatum.}

Next we explored possible mechanisms for the regulation of HTT/mHTT levels by SUMO1 in the striatum. We focused on p62, a selective macro-autophagy receptor that sequesters ubiquitinylated proteins and regulates protein aggregation [125]. Moreover, previous studies have identified p62 as a critical mediator of HTT-induced selective autophagy and disease phenotype [30, 31, 120, 126-130]. We carried out p62 immunostaining in brain sections. By applying fluorescence colocalization analysis using Manders overlap coefficient (MOC) [131, 132] we found that p62 strongly associated with EM48+ aggregates in Q175DN striatum and the association was significantly diminished in the Q175DN-SUMO1KO striatum (arrowhead, Fig. 5A, B).

Simultaneous binding occurs between p62 and autophagosomes via the interaction with LC3B-II and between p62 and mHTT/HTT [133, 134]. We used the MOC to examine the association of EM48+ mHTT and LAMP1 (a lysosomal marker), the association between LC3B-II (an autophagosome marker) and LAMP1, and the p62 and LAMP1 co-localizations. We found strong increases in the EM48+ association with LAMP1 (arrowhead, Fig. 5C, D), as well as enhanced interaction between LC3B-II and LAMP1 (arrowhead, Fig. 5E, F). By contrast, the p62 and LAMP1 association was diminished in the Q175DN-SUMO1KO striatum compared to the Q175DN striatum (arrowhead, Fig. 5G, H).

These confocal microscopy results suggested that SUMO1 deletion may enhance autophagic activities in the HD striatum. We then separated lysosomes using sucrose density gradient centrifugation and found enhanced p62 and LC3B-II accumulation in the lysosomal fractions in the Q175DN-SUMO1KO (green oval) compared to the Q175DN striatum (red oval) (Fig. 5I). The SUMO1KO mice also displayed enhanced p62 and LC3- 
II accumulation (blue rectangle) in the lysosomal fraction compared to the WT (black rectangle).

Collectively, these results indicate that SUMO1 deletion enhances autophagy activities in the HD striatum.

\section{SUMO1 deletion increases autophagy flux in a cellular model of HD.}

We next used cultured HD striatal cells to examine the cause-and-effect relationship between SUMO1 and autophagy regulation. We depleted SUMO1 by CRISPR/Cas-9 in well-established STHdh ${ }^{\mathrm{Q7/Q7}}$ (WT control) and STHdh $h^{\mathrm{Q7/Q111}}$ (HD-het) cell lines [135] and successfully depleted $\sim 50-60 \%$ of the SUMO1 modifications (Fig. 6A, B). The steady state levels of HTT were not significantly affected by diminished SUMOylation (Fig. 6A, B). The HD-het cells showed enhanced basal LC3B-II compared to WT control and the levels were not affected by SUMO1 depletion (Fig. 6A, B). By contrast, enhancement of p62 in HD-het cells was diminished by SUMO1 depletion (Fig. 6A, B). Confocal analysis of SUMO1-depleted (SUMO1A) control and HD-het cells showed that colocalization (MOC) of EM48 - p62 (Fig. 6 C, D), LAMP1 - p62 (Fig. 6 E, F), and EM48 - LAMP - p62 (Fig. $6 \mathrm{G}, \mathrm{H}$ ) were decreased in SUMO1ऽ HD-het cells compared to SUMO1 intact HDhet (control) cells. These results suggest that autophagy activities are increased upon SUMO1 deletion in HD cells.

Biochemical fractionation experiments further confirmed an increased autophagic activity, namely the high LC3B-II association (orange circle) and the diminished p62 levels (green circle) in the lysosomal compartment, in SUMO1ム HD-het cells compared to ctrl HD-het cells (Fig. 6I). Assessment of autophagy flux with chloroquine showed further accumulation of LC3B-II and p62 in the SUMO1D HD-het cells (Fig. 6J), suggesting that SUMO1 deletion most likely increases autophagy flux in HD.

Unlike the in vivo paradigm, we did not observe any drastic decline in basal HTT levels in SUMO1ऽ HD-het cultured cells (Fig. 6A, B). One reason could be that steadystate effect of SUMO1 on MHTT degradation by autophagy cannot be distinguishable from its synthesis. So, we carried out kinetics experiments with protein synthesis inhibitor cycloheximide ( $\mathrm{CHX}$ ) and found that both $\mathrm{mHTT}$ and poly-Q $\mathrm{mHTT}$ levels were strongly diminished in the presence of $\mathrm{CHX}$ in the SUMO1 $\triangle$ HD-het cells compared to the WT control (Fig. 6K, L). We also observed more autophagic activity evident by increasesd 
LC3B-II expression and decreased p62 in the SUMO1 1 HD-het cells (Fig. 6K, L). We did not detect any change in the normal HTT levels, further indicating that in vivo regulation of HTT by SUMO1 is perhaps regulated in a tissue- and age-dependent manner (Fig. 6K, \llcorner) . These results indicate SUMO1 deletion diminishes mHTT levels by enhancing autophagic activities.

\section{The SUMOylation inhibitor ginkgolic acid (GA) enhances autophagy in neuronal HD cells and human HD fibroblasts.}

We then examined whether the pharmacological modulation of SUMOylation affected autophagy activities in HD cells. To determine this, we investigated the effect of ginkgolic acid (GA). GA, an extract from Ginkgo biloba leaves, is a type of alkyl phenol that can directly bind SUMO-activating enzyme, E1, and inhibit the formation of the E1SUMO intermediate, thereby diminishing SUMOylation [136-140]. Because SUMO1 depletion enhanced autophagic activities in HD, we hypothesized that GA might enhance the autophagy activities and alter HTT levels in HD cells. We tested the GA effect in WT control, HD-het striatal neuronal cells and human unaffected with 17CAG repeats and HD-het fibroblasts that contain mHTT with 69 CAG repeats (this is closer to the form of mHTT in juvenile HD).

Treatment with GA $(100 \mu \mathrm{M})$ did not cause observable toxicity but resulted two major effects. First, at $0 \mathrm{hr}, \mathrm{GA}$ induced a remarkable upregulation of LC3B-II and p62 expression in striatal cells (Fig. 7A, B) as well as fibroblasts (Fig. 7C, D). Second, upon time course experiments with $\mathrm{CHX}$, the GA treatment did not affect normal HTT or mTOR levels both in WT striatal neuronal cells (Fig. 7A, B) and unaffected fibroblasts (Fig. 7C, D). However, GA showed a strong trend of diminished $\mathrm{mHTT}$ levels, particularly evident with poly- $Q$ antibodies in both cell types, and the diminishing effect of GA appeared more pronounced in human HD fibroblast (Fig. 7B, D). Moreover, in $\mathrm{CHX}$ treatment, we observed time-dependent rapid degradation of autophagic cargo, p62, in HD striatal cells and human fibroblast cells in presence of GA compared to vehicle treated controls. This data clearly indicate SUMOylation inhibitor GA promotes robust autophagy and rapid clearance of autophagy cargo. The effect of GA is specific to $\mathrm{mHTT}$ because GA did not influence normal HTT or mTOR levels compared to vehicle controls (Fig. 7A-D). These 
results indicate that GA mimics SUMO1 depletion and potentiates autophagy activities and diminishes mHTT protein levels in both mouse and human HD cells.

\section{DISCUSSION}

Although polyglutamine expansion is sufficient for pathogenesis, the toxicity of mHTT is altered by additional cis/trans regulators. Previous studies have revealed that SUMO is a trans-acting regulator of mHTT toxicity in HD cells and in HD animal models [83, 84, 86, 141]. SUMO modification of $\mathrm{mHTT}$ has been shown previously to increase the soluble forms and to promote cellular toxicity [142-144], but no in vivo role or underlying mechanism for SUMOylation has been proposed for HD pathogenesis in knock-in model.

The present data reveal that SUMO1 deletion in the Q175DN HD-het knock-in mice diminished HD-related behavioral and anatomical deficits and inflammatory responses and was accompanied by the enhancement of EM48+/p62 localization, autophagy, and lysosomal activities in the striatum. Interestingly, the SUMO1-deleted MSNs showed alteration of $\mathrm{mHTT}$ from a soluble to an aggregated state, and the aggregates were then further reallocated from the nucleus and extracellular space to the cytoplasm. Thus, SUMO1 regulation of HD pathogenesis is accompanied by altered autophagy signaling and a potentially neurotoxic localization of soluble forms of mHTT in the cytoplasm. Notably, only a limited number of gene transcripts and the associated inflammatory biomarkers were altered in the striatum of SUMO1-deleted HD mice. These results reveal that the possible mechanism(s) may involve post-transcriptional regulation of SUMO signaling and an important autophagy regulatory mechanism in the mediation of mHTT-induced striatal atrophy.

Previous studies have linked SUMOylation to autophagy. For example, SUMOylation of Vps34 and its interaction with Beclin-1 is implicated in autophagosome formation in cancer and smooth muscle cells [76, 145]. Similarly, the SUMO E2 ligase Ubc9 can regulate autophagy flux in cardiomyocytes[146]. Upon DNA damage, SUMOylation of RhoB promotes its interaction with TSC2 and translocation to the lysosomes, where it inhibits mTORC1 to result in activation of autophagy [147]. Furthermore, deletion of the Senp3 gene that codes for a de-sumoylating enzyme increased autophagy flux in the liver [148]. These results suggest that SUMOylation 
promotes autophagy flux. By contrast, blocking the SUMO pathway by depleting SUMO1 and UBC9 or by exposure to ginkgolic acid (a SUMOylation inhibitor) enhances the autophagy flux in breast cancer cells [149]. Thus, SUMOylation can modulate autophagy in two opposite directions, depending on the cell/tissue type, regulator, and targets of the SUMO pathway being altered. Therefore, a highly complex and intricate regulation of SUMOylation is associated with autophagy signaling.

Our results indicate SUMO1 in HD inhibits autophagy and that the mechanisms may involve a combination of multiple molecular processes. For example, SUMO1 modification of mHTT may directly interfere with the autophagy components; consequently, a loss of SUMO1 increases the levels of the ubiquitinated version of mHTT that, in turn, can interact strongly with p62 to enhance macroautophagy as well as mHTT clearance (Fig. 7E). This possibility is supported by our results showing enhanced autophagy activities and degradation of soluble mHTT in SUMO1-deleted HD striatum and cell models. SUMO may also inhibit autophagy via an indirect and integrated inhibitor feedback loop. For instance, 1) SUMO modification of $G \beta L$, which is a major component of mTOR, regulates nutrient-induced mTORC1 signaling, which inhibits autophagy [18, 150]. 2) SUMO modification of mHTT, which also promotes nutrient-induced mTORC1 signaling[100], may further inhibit autophagy [150]. And 3) SUMOylation of Rhes on multiple sites may regulate Rhes-mediated Beclin-1-dependent and mTORC1independent autophagy [82, 151]. Thus, SUMO deletion may regulate autophagy in the striatum via both mTORC1-dependent and mTORC1-independent signaling pathways.

We propose a model (Fig. 7E) whereby $\mathrm{mHTT}$ is synthesized and then undergoes SUMO modification, mediated by one or more SUMO E3-like proteins, such as Rhes [81, 82, 86], PIAS [83, 141], or unknown E3s. Both the non-SUMOylated and SUMOylated versions of mHTT can move into the nucleus and out of the neurons (into the extracellular space) and eventually become aggregated. A portion of the non-SUMOylated HTT that aggregates in the cytoplasm is removed by the ubiquitin and p62 interaction through autophagy or other degradation pathways, such as proteasomes $[152,153]$. By contrast, the SUMOylated soluble mHTT forms inhibit autophagy, either by activating mTORC1 or blocking autophagosome formation or lysosomal activities [134, 154, 155]. Thus, SUMO1 causes a slow and sustained blockade of autophagy, thereby affecting neuronal 
homeostasis and leading to the MSN dysfunction observed in HD (Fig. 7E, left panel). Lack of SUMO1 averts this autophagy inhibition and impedes the transport of mHTT to the nucleus and extracellular space. This enhances the formation of mHTT aggregates in the cytoplasm, and these can now be degraded through the active autophagy pathway (Fig. 7E, right panel).

Surprisingly, the SUMO E3-like protein Rhes levels are downregulated in the Q175DN HD and Hdh150Q knock-in mouse striatum (data not shown), indicating that compensatory mechanisms are at work. Perhaps clearance of Rhes will decrease the SUMOylated forms of mHTT and extend the onset and reduce the severity of the disease process. Consistent with this notion, forced expression of Rhes enhanced soluble forms of mHTT and worsened the motor phenotype in HD mouse models[92].

Overall, this report, based on data integrated from in vivo models, behavioral approaches, and biochemical tools, provides insights into a critical role of SUMO in autophagy regulation. SUMO1 deletion reduces the soluble $\mathrm{mHTT}$ levels, prevents the inflammatory response, and ameliorates HD pathogenesis. This research shows that interfering with SUMO signaling for example by using pharmacological inhibitor such as GA or its analogs can provide therapeutic opportunities to relieve HD symptoms and progression by upregulating autophagy and diminishing toxic mHTT levels.

\section{MATERIALS AND METHODS}

\section{Reagents and antibodies}

All reagents were purchased from Millipore-Sigma unless indicated otherwise. The following commercial antibodies were used: Huntingtin (WB-1:3000 clone 1HU-4C8, no. MAB2166), EM48 huntingtin (WB-1:10000, IHC-1:250, no. MAB5374), and Antipolyglutamine (poly-Q) antibody (WB-1:5000, no. P1874) antibodies were obtained from Millipore-Sigma. Antibody against GFAP (IHC-1:500, 13-0300) was from ThermoFisher Scientific and LAMP1 (WB-1:1000, 1:200 (IHC), no. 1D4B) was from Developmental Studies Hybridoma Bank. Antibodies for DARPP-32 (WB-1:20000, IHC-1:500, no. 2306), SUMO1 (WB-1:1000, no. 4930), p62 (WB-1:1000, no. 39749), p62 (WB-1:1000, IHC1:200, no. 23214), p62 (WB-1:1000, no. 7695), SDHA (WB-1:1000, no. 11998), LC3B 
(WB-1:2000, IHC-1:200, no. 3868), and mTOR (WB-1:3000, no. 2983) were from Cell Signaling Technology. Antibodies for $\beta$-actin (WB-1:20,000; no. sc-47778), glyceraldehyde-3-phosphate dehydrogenase (Gapdh) (WB-1:1000; no. sc-32233) were obtained from Santa Cruz Biotechnology. HRP-conjugated secondary antibodies: goat anti-mouse (1:10,000; no.115-035-146, goat anti-rabbit (1:10,000; no. 111-035-144) and goat anti-rat (1:10,000; no. 112-035-143) were from Jackson ImmunoResearch Inc. Donkey anti-Mouse Alexa Fluor 488 (1:500, no. A21202), Donkey anti-Mouse Alexa Fluor 568 (1:500, no. A10037), Donkey anti-Mouse Alexa Fluor 647 (1:500, no. A31571), Donkey anti-Rabbit Alexa Fluor 488 (1:500, no. A21206), Donkey anti-Rabbit Alexa Fluor 568 (1:500, no. A10042), Donkey anti-Mouse Alexa Fluor 647 (1:500, no. A31573), Donkey anti-Mouse Alexa Fluor 568 (1:500, no. A10037), and Donkey anti-Rat Alexa Fluor 594 (1:500, no. A21209)-conjugated secondary antibodies were from ThermoFisher Scientific.

\section{Animals}

Sumo1 knock out mice (SUMO1KO) were obtained from Jorma Palvimo [78]. zQ175 neodeleted knock-in heterozygous (Q175DN HD-het, \#029928) and C57BL/6J control mice were from Jackson laboratories. Q175DN (HD-het) and SUMO1KO mice were bred to produce Q175DN-SUMO1KO and littermate groups, Q175DN (Het), SUMO1KO and WT, and the genotypes were confirmed by an established PCR protocol. Behavior evaluation was performed as indicated in the timeline Figure 1A. Number of animals used are indicated in Table 1.

Table 1: Details of mice

\begin{tabular}{|l|c|c|c|}
\hline Genotype & Male & Female & Total \\
\hline WT & 22 & 15 & 37 \\
\hline Q175DN & 19 & 9 & 28 \\
\hline Q175DN-SUMO1KO & 13 & 17 & 30 \\
\hline SUMO1KO & 15 & 12 & 27 \\
\hline
\end{tabular}

\section{Cell lines and treatments}

Mouse STHdh ${ }^{Q 7 / Q 7}(\mathrm{CH} 00097)$ and $S T H d h^{Q 7 / Q 111}$ (CH00096) striatal neuronal cells, HD patient-derived fibroblast cell lines [wild type HTT allele/17 CAG repeats, mutant HTT allele/69 CAG repeats (GM04281)] and normal human fibroblast cell line (GM07492) 
were obtained from Coriell Institute for Medical Research (Camden, New Jersey, USA). Striatal cells were cultured in DMEM high glucose (10566-016, ThermoFisher Scientific), $10 \% \mathrm{FBS}, 5 \% \mathrm{CO} 2$, at $33^{\circ} \mathrm{C}$ as described in our previous works[22, 85, 86, 100, 156158]. Human fibroblasts were maintained at $37^{\circ} \mathrm{C}$ and $5 \% \mathrm{CO}_{2}$ in DMEM, high glucose, GlutaMAX supplement supplemented with 10\% FBS, $1 \%$ penicillin-streptomycin and $1 \%$ MEM nonessential amino acids (ThermoFisher Scientific). SUMO1 deletion was carried out in striatal cells using CRISPR/Cas-9 tools obtained from Santa Cruz, as described before[85, 157]. Cycloheximide (CHX, no. C1988, Millipore Sigma) was dissolved in $95 \%$ ethanol and used at $75 \mu \mathrm{M}$ (striatal cells) or $50 \mu \mathrm{M}$ (human fibroblasts) for indicated time points. To assess autophagy flux, cells were pretreated with chloroquine (CQ, 50 $\mu \mathrm{M}$, no. C6628, Millipore Sigma) for $4 \mathrm{hr}$, then proceeded for subcellular fractionation as described below. Stock solution (25 mM) of Ginkgolic acid (GA, no. 6326, Tocris Bioscience) was prepared in DMSO. Striatal cells or human fibroblasts were treated with $100 \mu \mathrm{M}$ GA and after $12 \mathrm{hrs}$ CHX was added for indicated time points (total time of GA treatment was for $24 \mathrm{hrs}$ )

\section{Subcellular Fractionation}

For subcellular fractionations, mice were euthanized and both striata were dissected immediately and homogenized using a glass dounce homogenizer (5 loose and 5 tight strokes) in buffer A of mitochondria isolation buffer (ThermoFisher Scientific, no. 89874) and kept on ice for 2 minutes. Buffer $\mathrm{C}$ was added to each sample and mixed by inverting 5 times. The homogenates were centrifuged at low speed $(700 \mathrm{~g})$ for 10 minutes to separate nuclei and tissue chunks. The supernatants were immediately loaded on top of $10-50 \%$ sucrose gradients and centrifuged at 40000 RPM (SW41Ti rotor) at $4^{\circ} \mathrm{C}$ for 2 hours. The gradients were fractionated manually (11 or $13 \times 1 \mathrm{ml}$ fractions). Using methanol/chloroform, total protein of each fraction was precipitated. The protein pellets were resuspended in 2X LDS buffer and used for western blotting as described below. All the samples were proceeded at the same time. During developing the blots, all the groups were developed at the same time with corresponding antibody. For striatal neuronal cell fractionation, cells were resuspended in buffer $A$ of mitochondria isolation buffer after harvesting and pelleting in PBS. Lysates were kept on ice for 2 minutes and were passed 
15 times through a 26-gauge needle and syringe. Lysates were proceeded for subcellular fractionation as mentioned above for striatum samples.

\section{Western blotting}

Striatal tissue were rinsed briefly in PBS and directly lysed in lysis buffer [50 mM Tris- $\mathrm{HCl}(\mathrm{pH} 7.4), 150 \mathrm{mM} \mathrm{NaCl}, 1 \%$ Triton X-100, 1x protease inhibitor cocktail (Roche, Sigma) and $1 \times$ phosphatase inhibitor (PhosStop, Roche, Sigma)], sonicated for $2 \times 5$ sec at $20 \%$ amplitude, and cleared by centrifugation for $10 \mathrm{~min}$ at $11,000 \mathrm{~g}$ at $4^{\circ} \mathrm{C}$. Striatal cells or human fibroblasts were lysed in radioimmunoprecipitation assay (RIPA )buffer [50 $\mathrm{mM}$ Tris- $\mathrm{HCl}$ ( $\mathrm{pH} 7.4), 150 \mathrm{mM} \mathrm{NaCl}, 1.0 \%$ Triton $\mathrm{X}-100,0.5 \%$ sodium deoxycholate, $0.1 \%$ SDS] with $1 \times$ complete protease inhibitor cocktail and $1 \times$ phosphatase inhibitor , followed by a brief sonication for $2 \times 5 \mathrm{sec}$ at $30 \%$ amplitude and cleared by centrifugation for $10 \mathrm{~min}$ at $11,000 \mathrm{~g}$ at $4^{\circ} \mathrm{C}$. Protein concentration was determined with a bicinchoninic acid (BCA) protein assay reagent (Pierce). Equal amounts of protein (20-50 $\mu \mathrm{g}$ ) were loaded and were separated by electrophoresis in 4 to $12 \%$ Bis-Tris Gel (ThermoFisher Scientific), transferred to polyvinylidene difluoride membranes, and probed with the indicated primary antibodies. HRP-conjugated secondary antibodies were probed to detect bound primary IgG with a chemiluminescence imager (Alpha Innotech) using enhanced chemiluminescence from WesternBright Quantum (Advansta) The band intensities were quantified with ImageJ software (NIH). Total proteins were then normalized to actin or Gapdh.

\section{Immunohistochemistry}

Immuno-histochemistry was performed as described in our previous work[159, 160]. Briefly, mice were anesthetized and perfused with saline $\left(4^{\circ} \mathrm{C}\right)$ and after with $4 \%$ PFA $\left(4^{\circ} \mathrm{C}\right)$. The whole brain was dissected and postfixed in PFA, cryoprotected by sucrose gradients treatment (10 to $30 \%$ ) at $4^{\circ} \mathrm{C}$ for 3 days and embedded in Tissue-Tek. Coronal sections (25 $\mu \mathrm{m}$ thick) were collected on Superfrost/Plus slides and immunostained with the indicated primary antibodies overnight at $4^{\circ} \mathrm{C}$. Sections were then incubated with secondary antibodies for $2 \mathrm{~h}$ at room temperature $(1: 250)$, counterstained with DAPI 
(Sigma-Aldrich) and mounted with Fluoromount-G mounting medium (ThermoFisher Scientific). Images were acquired by using the Zeiss LSM 880 confocal microscope system with a $20 \times / 63 \times$ objective.

GFAP quantification was made in whole striatal reconstructions from immunostained coronal sections. Using an LSM-800 Zeiss microscope in a tile scan/Z-stack configuration protocol and a 40X objective, we obtained $12 \mu \mathrm{m}$ thick reconstruction ( $3 \mu \mathrm{m}$ stack) from the right and left striatums from each brain section. They consisted of frontal, central, and caudal striatum regions, and about 1 - 3 sections for each striatal region per mouse were observed. GFAP fluorescence intensity was calculated in Z-stack reconstruction for all the groups. Confocal images were analyzed in ImageJ software.

Colocalization coefficient (Mander's coefficient) analyses and cell quantification for IHC were made in single-plane confocal images to avoid false positive colocalization. Colocalization between DARPP-32 and EM48 was considered intracellular EM48 aggregates, EM48 without DARPP-32 colocalization was deemed extracellular aggregates. EM48 nuclear aggregates were confirmed by DAPI colocalization.

The lateral ventricular area was determined in hematoxylin/eosin-stained sections, from the same animals. Sections at rostral (+1.45 from bregma), central striatum $1(+1.0$ from bregma), central striatum 2 (+0.60 from bregma), and caudal (+0.1 from bregma) lateral ventricles at the striatum level from WT, Q175DN, Q175DN-SUMO1KO and SUMO1KO mice ( $n=5$ mice per group) were taken using the Leica DM5500B microscope (10x objective). The lateral ventricular area was calculated by analyzing the images using the ImageJ software. $\mathrm{N}=5$ mice per group, $3-4$ sections were analyzed and averaged for each striatal region per mouse.

\section{Immunocytochemistry}

Immunostaining was carried out as described in our previous work [100]. Briefly, striatal cells were grown on poly-D-lysine $(0.1 \mathrm{mg} / \mathrm{ml})$-coated glass coverslips and after 24 hours of plating, the medium was changed to Krebs buffer medium devoid of serum and amino 
acids for 1 hour to induce full starvation conditions. For the stimulation conditions, cells were stimulated with $3 \mathrm{mM}$ L-leucine for $15 \mathrm{~min}$. Cells were washed with cold PBS, fixed with 4\% paraformaldehyde (PFA; $20 \mathrm{~min}$ ), treated with $0.1 \mathrm{M}$ glycine, and permeabilized with $0.1 \%$ (v/v) Triton X-100 (5 min). After being incubated with blocking buffer [1\% normal donkey serum, 1\% (w/v) BSA, and 0.1\% (v/v) Tween 20 in PBS] for 1 hour at room temperature, cells were stained overnight at $4{ }^{\circ} \mathrm{C}$ with antibodies against EM48, p62, and LAMP1. Alexa Fluor 488- or Alexa Fluor 568-conjugated secondary antibodies were incubated together with the nuclear stain DAPI for 1 hour at room temperature. Glass coverslips were mounted with Fluoromount-G mounting medium (ThermoFisher Scientific). Images were acquired by using the Zeiss LSM 880 confocal microscope system with a $63 \times$ objective.

\section{Behavioral analysis}

Open field

An open-field test was used to measure the total activity. Briefly, animals were placed in the center of each square $(50 \mathrm{~cm} \times 50 \mathrm{~cm})$ open-top box under bright light and recorded via a ceiling-mounted video camera for $15 \mathrm{~min}$. Locomotor activity was assessed using the EthoVision XT 11.5 animal tracking software (Noldus) and showed the total distance traveled. Before open field performance, all the mice were kept in a waiting room for 30 min. Open-field test was made every two months before Rotarod and beam walk evaluation.

\section{Rotarod}

The accelerating rotarod test was used to quantify motor alterations in all the genotypes. Before evaluation day, all the mice were trained for $3 \mathrm{~min}$ in a no-accelerating rod (20 rpm) for two consecutive days. On the day of the test, all the mice were challenged in an accelerating rod (4 to $40 \mathrm{rpm}$, with a cut off of $5 \mathrm{~min}$ ), and the average of the latency to fall for three trials was used for the analysis $(20 \mathrm{~min}$ of resting were used between each trial). Rotarod was evaluated every two months old, starting at two months after born. 


\section{Beam walk}

Alterations of the motor coordination also were evaluated using the beam walk test. The beam walk system consisted of the suspended beam (100 cm long) at $50 \mathrm{~cm}$ high with a chamber $(12 \times 12 \times 12 \mathrm{~cm})$ at the end of a $100 \mathrm{~cm}$ long beam. Every two months, all the mice were trained for three days to cross a beam. On the first day of the training, we used a $12 \mathrm{~mm}$ width beam; for the second day, we used a $9 \mathrm{~mm}$ width beam, and on the third day (evaluation day), a $6 \mathrm{~mm}$ width beam was used. For each evaluation session, three trials were made with 10 min between them. The average time to cross the beam (100 $\mathrm{cm}$ ) was recorded on the evaluation day. Before the trials and between them, the mice were kept in the beam walk chamber.

\section{Behavioral battery evaluation}

The behavior battery evaluation was done at 13 months old; each test was performed in triplicate, measured ledge walking, clasping, gait, kyphosis, and tremor. Individual measures were scored on a scale of 0 (absence of relevant phenotype) to 3 (most severe manifestation), as described previously [100, 161], with the addition of testing for tremor. To determine tremor, mice were placed in a clean cage and observed for 30 seconds. Each mouse was scored as follows: 0 , no signs of tremor; 1 , present but mild tremor; 2 , severe intervals of tremor or constant moderate tremor; 3 , extreme chronic tremor. The composite score was generated as the mean of all five behavioral battery tests.

\section{RNA seq}

Three striatum samples from each genotype (WT, Q175DN, Q175DN-SUMO1KO and SUMO1KO) were lysed in Trizol reagent. RNA was extracted from miRNeasy kit from Qiagen (cat. No. 217004) and RNA-seq and IPA were performed in Scripps Genomics and Bioinformatics Core, Jupiter, FL, USA as described[22].

\section{Statistical analysis}

Data are presented as mean \pm SEM as indicated. Except where stated all experiments were performed at least in biological triplicate and repeated at least twice. The mouse behavioral and the data analysis was carried out in a blinded manner. Images were 
quantified using ImageJ (FIJI). Behavioral data consisted of categorical and continuous outcomes. Categorical data was analyzed using Fisher's Exact test. Statistical comparison was performed between groups using two-tailed Student's t-test, one-way analysis of variance (ANOVA) followed by Tukey's multiple comparison test or Bonferroni's multiple comparisons test and two-way ANOVA or repeated measure twoway ANOVA or two-way ANOVA mixed-effects model (REML) followed by Tukey's multiple comparison test or Bonferroni post-hoc test as indicated in the figure legends. Significance was set at $p<0.05$. All statistical tests were performed using Prism 9.0 (GraphPad software).

\section{Data availability}

Sequencing data have been submitted to the Gene Expression Omnibus (GEO) data repository.

Acknowledgments: We would like to thank Melissa Benilous for her administrative help and the members of the lab for their continuous support and collaborative atmosphere.

We like to thank members at the Scripps proteomics and genomic core for their help and expertise. This research was partially supported by a training grant in Alzheimer's drug discovery from the Lottie French Lewis Fund of the Community Foundation for Palm Beach and Martin Counties; grant awards from NIH/NINDS R01-NS087019-01A1, NIH/NINDS R01-NS094577-01A1, a grant from Cure for Huntington Disease Research Initiative (CHDI) foundation and Scripps bridge funding.

Author contributions: S.S and N.S conceptualized the project and co-designed experiments with U.N.R.J. who performed mouse behavior experiments, immunohistochemistry, immunostaining, confocal, colocalization analysis and analyzed the data. M.S., U.N.R.J. and N.S carried out SUMO deletion and Western blotting experiments and quantification. S.S and N.S and wrote the manuscript with inputs from coauthors. 


\section{FIGURE LEGENDS}

Figure1. Effect of SUMO1 deletion on age-associated motor abnormalities in Q175DN knock-in HD mice model. (A) Shows the genotypes, timeline and experimental design for the animal study. (B-G) Body weight and behavioral analysis at 2-12 months of age; Body weight $(B)$, rotarod $(C)$, beam walk $(D)$ and open field $(E)$, behavioral battery $(F)$, behavioral battery composite score $(G)$. Behavioral batteries included ledge-test, clasping, gait, kyphosis, and tremor evaluation. The frequency of each behavior according to the genotype is shown in $\mathrm{F}$, a composite score for all the behavioral battery is shown in G. Data are mean \pm SEM (WT, $n=37$, Q175DN, $n=28$, Q175DN-SUMO1KO, $n=30$, SUM01KO, $\mathrm{n}=27) .{ }^{*} P<0.05,{ }^{* * *} P<0.0001$ between $\mathrm{Q} 175 \mathrm{DN}$ and WT; ${ }^{*} P<0.05$, ${ }^{\#} P$ $<0.01$, and ${ }^{\# \#} P<0.001$ between Q175DN-SUMO1KO and Q175DN by two-way ANOVA mixed-effects model (REML) followed by Tukey's multiple comparison test (For B-E). ${ }^{* * * *} P<0.0001$ between Q175DN and WT; \#\#\# $P<0.0001$ between Q175DN-SUMO1KO and Q175DN by Fisher's exact test (for $F$ ), and ${ }^{* * * *} P<0.0001$ between Q175DN and WT; \#\#\# $P<0.001$ between Q175DN-SUMO1KO and Q175DN by one-way ANOVA followed by Tukey's multiple comparison test (for $\mathrm{G}$ ).

Figure 2. Effect of SUMO1 deletion on striatal anatomical changes and the striatal gene transcription in Q175DN mice. (A) Representative hematoxylin/eosin-stained sections for rostral ( +1.45 from bregma), central striatum 1 ( +1.0 from bregma), central striatum $2(+0.60$ from bregma), and caudal $(+0.1$ from bregma) lateral ventricles at the striatum level from the WT, Q175DN, Q175DN-SUMO1KO and SUMO1KO mice. (B) Quantification of the lateral ventricular area from A. Data are mean \pm SEM $(n=5$ mice per group, $3-4$ sections were analyzed and averaged for each striatal region per mouse). ${ }^{* * \star} P<0.001,{ }^{* * * *} P<0.0001$ between Q175DN and WT; ${ }^{\# \# \#} P<0.0001$ between Q175DN-SUMO1KO and Q175DN using two-way ANOVA followed by Tukey's multiple comparison test (C, D) IPA network analysis between WT vs Q175DN groups. (E) List of differentially regulated genes in striatum from Q175DN-SUMO1KO mice compared to Q175DN mice. (F) IPA analysis between Q175DN and Q175DN-SUMO1KO. 
Figure 3. SUMO1 deletion diminishes inflammatory astroglial response in Q175DN mice. (A) Representative confocal images for the frontal, central and caudal striatum showing DARPP-32 (green), and GFAP (red) IHC, and nuclear stain DAPI (blue) with the indicated magnified image in the insets from the WT, Q175DN, Q175DN-SUMO1KO and SUMO1KO mice. Insets, striatum (a, c, e, g) and cortex (b, d, f, h). (B) Quantification of the GFAP intensity from the frontal, central and caudal striatum. Data are mean \pm SEM, $\mathrm{n}=5$ mice per group, between 1 to 3 sections for each striatal region per mouse were analyzed (total 8 sections for WT, and 16 sections each for Q175DN, Q175DNSUMO1KO and SUMO1KO groups). ${ }^{* * * *} P<0.0001$ by one-way ANOVA followed by Tukey's multiple comparison test. (C) Western blots for the GFAP, DARPP-32 and Free SUMO1 expression for all the genotypes. (D) Quantification of the blots from C. Data are mean \pm SEM, $n=3$ mice per group for GFAP, $n=3$ mice per group for DARPP-32. ${ }^{*} P<$ 0.05 , and ${ }^{* * *} P<0.001$ by one-way ANOVA followed by Tukey's multiple comparison test . (E) TPM (Transcripts Per Kilobase Million) counts of GFAP and DARPP-32 mRNA from the RNA-seq from striatum of WT, Q175DN, Q175DN-SUMO1KO and SUMO1KO mice. Data are mean \pm SEM, $\mathrm{n}=3$ mice per group. ${ }^{* *} P<0.01$ by one-way ANOVA followed by Tukey's multiple comparison test. ${ }^{P} P<0.05$ by unpaired two-tailed Student's $t$ test.

\section{Figure 4. SUMO1 deletion alters EM48 aggregate distribution in the Q175DN mice} striatum. (A) Low magnification confocal immunofluorescence images showing GFAP (red), $\mathrm{Htt}$ aggregates (EM48+, green), and DARPP-32 (white) expression from Q175DN and Q175-SUMO1KO brain sections. (B) Representative confocal images showing EM48 aggregates (green) and DARPP-32 (red) IHC and colocalization of EM48 aggregates and DARPP-32 in the striatum from Q175DN and Q175-SUMO1KO mice. (C) Bar graphs show the number of DARPP-32+ neurons in $100 \mu m^{2}$ area. Data are mean \pm SEM $(n=5$ mice per group, from each mouse 4 areas were averaged from 2-4 sections and section averages were used for analysis). n.s. not significant by two-tailed unpaired Student's ttest. (D) Mander's overlay coefficient of EM48 and DARPP-32 from B. Data are mean \pm SEM ( $n=5$ mice per group, from each mouse 4 areas were averaged from 2-4 sections and section averages were used for analysis). ${ }^{* * * *} P<0.0001$ by two-tailed unpaired Student's t-test. (E) Confocal images showing the EM48 aggregates (green), and 
DARPP-32 (red) IHC, and DAPI. Lower panels show the magnified insets depicting nuclear EM48+ aggregates (solid arrowhead), cytoplasmic EM48+ aggregates (open arrowhead) in the DARPP-32+ neuron, and extracellular EM48+ aggregates (asterisk). (F-J) Quantifications for the total number of cells (DAPI+) (F), total EM48+ aggregates $(G)$, number of neurons with nuclear EM48+ aggregates $(H)$, number of extracellular EM48+ aggregates (I) number of neurons with cytoplasmic aggregates $(\mathrm{J})$ in $100 \mu \mathrm{m}^{2}$ area. Data are mean \pm SEM ( $n=5$ mice per group, from each mouse 4 areas were averaged from 2-4 sections and section averages were used for analysis). ${ }^{* * *} P<0.001$, n.s. not significant by two-tailed unpaired Student's t-test. (K) Represntative western blot for indicated proteins from the striatum of WT, Q175DN, Q175DN-SUMO1KO and SUMO1KO mice. (L-N) Quantification of the EM48 aggregates (L), Htt levels (MAB2166) $(\mathrm{M})$ and PolyQ $(\mathrm{N})$ from K. Data are mean \pm SEM $\left(\mathrm{n}=3-9\right.$ mice per genotype). ${ }^{*} P<0.05$ by two-tailed unpaired Student's t-test; ${ }^{* * *} P<0.001,{ }^{* * * *} P<0.0001$, by one-way ANOVA followed by Tukey's multiple comparison test. (O) TPM (Transcripts Per Kilobase Million) counts of $H t t$ RNA from the RNA-seq from striatum of WT, Q175DN, Q175DN-SUMO1KO and SUMO1KO mice. Data are mean $\pm \operatorname{SEM}\left(\mathrm{n}=3\right.$ independent experiments). ${ }^{*} P<0.05$, by one-way ANOVA followed by Tukey's multiple comparison test. ${ }^{\#} P<0.01$ by twotailed unpaired Student's t-test.

Figure 5. SUMO1 deletion enhances autophagic activities in the striatum. $(A-H) I H C$ and quantification for colocalization coefficients for EM48 - p62 (A, B), EM48 - LAMP1 $(C, D)$, LC3B - LAMP1 $(E, F)$ and p62 - LAMP $1(G, H)$ in the striatum from Q175DN and Q175-SUM01KO mice. DAPI (blue) and color channels (green or red) according to indicated antibody combination. Insets with magnified images is shown on the right. Yellow arrowheads indicate the colocalization for green and red channels. Data are mean \pm SEM ( $n=5$ mice per group, from each mouse 4 areas were averaged from 2-4 sections and section averages were used for analysis). ${ }^{* *} P<0.001,{ }^{* * * *} P<0.0001$ by two-tailed unpaired Student's t-test. (I) Western blot of the biochemical fractionation from striatal tissues of indicated genotypes. Purple and orange rectangles show lysosomal and mitochondrial fractions, respectively. Dotted rectangle and oval show enrichment of indicated proteins. 
Figure 6. SUMO1 deletion increases the autophagy in a cellular model of HD. (A). Western blotting of the indicated proteins in control (ctrl) and SUMO1 deleted (SUMO $\Delta$ ) control and HD-het striatal cells. (B) Quantification of the indicated proteins from A. Data are mean $\pm \operatorname{SEM}\left(\mathrm{n}=3-4\right.$ independent experiments). ${ }^{* *} P<0.01,{ }^{* *} P<0.001$, by oneway ANOVA followed by Tukey's multiple comparison test. (C-H) Confocal images and corresponding magnified insets of control (ctrl) and SUMO1 deleted (SUMOA)-HD-het cells, immunostained and showing quantification of Mander's colocalization coefficient for EM 48 - p62 (C, D), LAMP1 - p62 (E, F) and EM48 - LAMP1 - p62 (G, H). Data are mean \pm SEM ( $n=4$ independent experiments, from each experiment two-three100 $\mu^{2}$ areas were quantified and used for group analysis). ${ }^{* * *} P<0.0001$ by two-tailed unpaired Student's t-test. (I, J) Western blot for the biochemical fractionation assay from control (ctrl) and SUMO1 deleted (SUMO $\Delta$ ) cells and without (I) or with chloroquine, CQ $50 \mu \mathrm{M}$ (J) treatment in HD-het cells. Purple and orange rectangles show lysosomal and mitochondrial fractions, respectively. Dotted oval show enrichment of indicated proteins. (K) Representative western blot of indicated proteins from ctrl and SUMO $\triangle$ cells with cycloheximide $(\mathrm{CHX}, 75 \mu \mathrm{M})$ treatment for the indicated time points. (L) Quantification of indicated proteins from K, normalized with GAPDH. Data presented as mean \pm SEM $(n=$ 4 independent experiments), ${ }^{*} P<0.05,{ }^{* *} P<0.01$, and ${ }^{* *} P<0.001$ HD-het (SUMO $\Delta$ ) vs HD-het (ctrl) cells, by repeated measure two-way ANOVA followed by Tukey's multiple comparison test or Bonferroni's multiple comparisons test (for PolyQ). n.s: not significant.

Figure 7. SUMO inhibition by Ginkgolic acid (GA) decreases stead-state-levels of mHTT in HD striatal and human HD fibroblasts. (A) Representative western blot for the indicated proteins from control and HD-het cells treated with vehicle (DMSO) or Ginkgolic acid (GA, $100 \mu \mathrm{M})$ for $24 \mathrm{hr}$ and $\mathrm{CHX}(75 \mu \mathrm{M})$ for indicated time points. (B) Quantification of indicated proteins from A, normalized with GAPDH (vehicle treated control cells as $100 \%)$. Data presented as mean \pm SEM $(n=3$ independent experiments), ${ }^{*} P<0.05,{ }^{* *} P<0.01,{ }^{* * *} P<0.001$, and ${ }^{* * *} P<0.0001$ between control and control $+\mathrm{GA}$; ${ }^{\#} P<0.05$, and ${ }^{\# \#} P<0.01$ between HD-het and HD-het + GA by repeated measure twoway ANOVA followed by Tukey's multiple comparison test or Bonferroni's multiple 
comparisons test (for PolyQ). (C) Human fibroblasts healthy or patient-derived HD cells (HD 69) treated with GA $(100 \mu \mathrm{M})$ for $24 \mathrm{hr}$ and $\mathrm{CHX}(50 \mu \mathrm{M})$ for indicated time points. (D) Data presented as mean \pm SEM ( $\mathrm{n}=3$ independent experiments), ${ }^{*} P<0.05$, and ${ }^{* *} P$ $<0.01$ between healthy and healthy + GA; ${ }^{\#} P<0.05$, ${ }^{\#} P<0.01$, and ${ }^{\# \# \# P} P<0.0001$ between HD69 and HD69 + GA by repeated measure two-way ANOVA followed by Tukey's multiple comparison test or Bonferroni's multiple comparisons test (for PolyQ).

(E) A mechanistic model depicting SUM01-mediated striatal abnormalities in HD. Left panel. A properly folded mHTT protein is modified by SUMO1 keeping it as an enhanced state of solubility. Non SUMOylated, improperly folded $\mathrm{mHTT}$ can aggregate, which are capable of being degraded by autophagy or another degradation system. But SUMOylated mHTT may block autophagy by various means either by upregulating mTORC1 or by blocking one or more other steps in the autophagy assembly. The presence of SUMO1 may also enhance the export of mHTT to the nucleus and to the extracellular space, which may eventually get aggregated but cannot be degraded due to lack of degradation machinery. Right panel. Lack of SUMO1 relieves inhibitory effect on autophagy. More mHTT gets aggregated in the cytoplasm and are degraded via autophagy and other degradation pathway. This process diminishes the transport of mHTT to the nucleus as well as extracellular space. Collectively, mHTT toxic effects are eliminated upon deletion of SUMO1.

Supplementary Figure 1. (A, B) IPA network analysis between WT and SUMO1KO mice and SUMO1KO and Q175DN mice.

\section{References:}

1. Difiglia, M., E. Sapp, K. Chase, C. Schwarz, A. Meloni, C. Young, E. Martin, J.P. Vonsattel, R. Carraway, S.A. Reeves, and et al., Huntingtin is a cytoplasmic protein associated with vesicles in human and rat brain neurons. Neuron, 1995. 14(5): p. 107581.

2. Hoffner, G., P. Kahlem, and P. Djian, Perinuclear localization of huntingtin as a consequence of its binding to microtubules through an interaction with beta-tubulin: relevance to Huntington's disease. J Cell Sci, 2002. 115(Pt 5): p. 941-8. 
3. Velier, J., M. Kim, C. Schwarz, T.W. Kim, E. Sapp, K. Chase, N. Aronin, and M. DiFiglia, Wild-type and mutant huntingtins function in vesicle trafficking in the secretory and endocytic pathways. Exp Neurol, 1998. 152(1): p. 34-40.

4. Brandstaetter, H., A.J. Kruppa, and F. Buss, Huntingtin is required for ER-to-Golgi transport and for secretory vesicle fusion at the plasma membrane. Dis Model Mech, 2014. 7(12): p. 1335-40.

5. Xia, J., D.H. Lee, J. Taylor, M. Vandelft, and R. Truant, Huntingtin contains a highly conserved nuclear export signal. Hum Mol Genet, 2003. 12(12): p. 1393-403.

6. Kegel, K.B., A.R. Meloni, Y. Yi, Y.J. Kim, E. Doyle, B.G. Cuiffo, E. Sapp, Y. Wang, Z.H. Qin, J.D. Chen, J.R. Nevins, N. Aronin, and M. DiFiglia, Huntingtin is present in the nucleus, interacts with the transcriptional corepressor $C$-terminal binding protein, and represses transcription. J Biol Chem, 2002. 277(9): p. 7466-76.

7. Zuccato, C., A. Ciammola, D. Rigamonti, B.R. Leavitt, D. Goffredo, L. Conti, M.E. MacDonald, R.M. Friedlander, V. Silani, M.R. Hayden, T. Timmusk, S. Sipione, and E. Cattaneo, Loss of huntingtin-mediated BDNF gene transcription in Huntington's disease. Science, 2001. 293(5529): p. 493-8.

8. Sipione, S., D. Rigamonti, M. Valenza, C. Zuccato, L. Conti, J. Pritchard, C. Kooperberg, J.M. Olson, and E. Cattaneo, Early transcriptional profiles in huntingtin-inducible striatal cells by microarray analyses. Hum Mol Genet, 2002. 11(17): p. 1953-65.

9. Nucifora, F.C., Jr., M. Sasaki, M.F. Peters, H. Huang, J.K. Cooper, M. Yamada, H. Takahashi, S. Tsuji, J. Troncoso, V.L. Dawson, T.M. Dawson, and C.A. Ross, Interference by huntingtin and atrophin-1 with cbp-mediated transcription leading to cellular toxicity. Science, 2001. 291(5512): p. 2423-8.

10. Zhang, H., S. Das, Q.Z. Li, I. Dragatsis, J. Repa, S. Zeitlin, G. Hajnoczky, and I. Bezprozvanny, Elucidating a normal function of huntingtin by functional and microarray analysis of huntingtin-null mouse embryonic fibroblasts. BMC Neurosci, 2008. 9: p. 38.

11. Takano, H. and J.F. Gusella, The predominantly HEAT-like motif structure of huntingtin and its association and coincident nuclear entry with dorsal, an NF-kB/Rel/dorsal family transcription factor. BMC Neurosci, 2002. 3: p. 15.

12. Steffan, J.S., A. Kazantsev, O. Spasic-Boskovic, M. Greenwald, Y.Z. Zhu, H. Gohler, E.E. Wanker, G.P. Bates, D.E. Housman, and L.M. Thompson, The Huntington's disease protein interacts with 53 and CREB-binding protein and represses transcription. Proc Natl Acad Sci U S A, 2000. 97(12): p. 6763-8.

13. Paul, B.D., J.I. Sbodio, R. Xu, M.S. Vandiver, J.Y. Cha, A.M. Snowman, and S.H. Snyder, Cystathionine gamma-lyase deficiency mediates neurodegeneration in Huntington's disease. Nature, 2014. 509(7498): p. 96-100.

14. Sbodio, J.I., S.H. Snyder, and B.D. Paul, Transcriptional control of amino acid homeostasis is disrupted in Huntington's disease. Proc Natl Acad Sci U S A, 2016. 113(31): p. 8843-8.

15. Tanimura, A., S.A. Lim, J.J. Aceves Buendia, J.A. Goldberg, and D.J. Surmeier, Cholinergic Interneurons Amplify Corticostriatal Synaptic Responses in the Q175 Model of Huntington's Disease. Front Syst Neurosci, 2016. 10: p. 102.

16. Plotkin, J.L., M. Day, J.D. Peterson, Z. Xie, G.J. Kress, I. Rafalovich, J. Kondapalli, T.S. Gertler, M. Flajolet, P. Greengard, M. Stavarache, M.G. Kaplitt, J. Rosinski, C.S. Chan, and D.J. Surmeier, Impaired TrkB receptor signaling underlies corticostriatal dysfunction in Huntington's disease. Neuron, 2014. 83(1): p. 178-88. 
17. Perez-Rosello, T., S. Gelman, G. Tombaugh, R. Cachope, V. Beaumont, and D.J. Surmeier, Enhanced striatopallidal gamma-aminobutyric acid (GABA)A receptor transmission in mouse models of huntington's disease. Mov Disord, 2019. 34(5): p. 684696.

18. Seibert, M., N. Kurrle, F. Schnutgen, and H. Serve, Amino acid sensory complex proteins in $\mathrm{mTORC1}$ and macroautophagy regulation. Matrix Biol, 2021.

19. Bae, B.I., H. Xu, S. Igarashi, M. Fujimuro, N. Agrawal, Y. Taya, S.D. Hayward, T.H. Moran, C. Montell, C.A. Ross, S.H. Snyder, and A. Sawa, 553 mediates cellular dysfunction and behavioral abnormalities in Huntington's disease. Neuron, 2005. 47(1): p. 29-41.

20. Bae, B.I., M.R. Hara, M.B. Cascio, C.L. Wellington, M.R. Hayden, C.A. Ross, H.C. Ha, X.J. Li, S.H. Snyder, and A. Sawa, Mutant huntingtin: nuclear translocation and cytotoxicity mediated by GAPDH. Proc Natl Acad Sci U S A, 2006. 103(9): p. 3405-9.

21. Chen, X., J. Wu, S. Lvovskaya, E. Herndon, C. Supnet, and I. Bezprozvanny, Dantrolene is neuroprotective in Huntington's disease transgenic mouse model. Mol Neurodegener, 2011. 6: p. 81.

22. Eshraghi M, K.P., Blin J, Shahani N, Ricci EP, Michel A, Urban N, Galli N, Sharma M, Ramírez-Jarquín UN, Florescu K, Hernandez J, and Subramaniam S, Mutant Huntingtin Stalls Ribosomes and Represses Protein Synthesis in a Cellular Model of Huntington disease. Nat Communication, 2021. In Press.

23. Lee, H., R.J. Fenster, S.S. Pineda, W.S. Gibbs, S. Mohammadi, J. Davila-Velderrain, F.J. Garcia, M. Therrien, H.S. Novis, F. Gao, H. Wilkinson, T. Vogt, M. Kellis, M.J. LaVoie, and M. Heiman, Cell Type-Specific Transcriptomics Reveals that Mutant Huntingtin Leads to Mitochondrial RNA Release and Neuronal Innate Immune Activation. Neuron, 2020. 107(5): p. 891-908 e8.

24. Shibata, M., T. Lu, T. Furuya, A. Degterev, N. Mizushima, T. Yoshimori, M. MacDonald, B. Yankner, and J. Yuan, Regulation of intracellular accumulation of mutant Huntingtin by Beclin 1. J Biol Chem, 2006. 281(20): p. 14474-85.

25. Fox, L.M., K. Kim, C.W. Johnson, S. Chen, K.R. Croce, M.B. Victor, E. Eenjes, J.R. Bosco, L.K. Randolph, I. Dragatsis, J.M. Dragich, A.S. Yoo, and A. Yamamoto, Huntington's Disease Pathogenesis Is Modified In Vivo by Alfy/Wdfy3 and Selective Macroautophagy. Neuron, 2020. 105(5): p. 813-821 e6.

26. Nagata, E., A. Sawa, C.A. Ross, and S.H. Snyder, Autophagosome-like vacuole formation in Huntington's disease lymphoblasts. Neuroreport, 2004. 15(8): p. 1325-8.

27. Petersen, A., K.E. Larsen, G.G. Behr, N. Romero, S. Przedborski, P. Brundin, and D. Sulzer, Expanded CAG repeats in exon 1 of the Huntington's disease gene stimulate dopamine-mediated striatal neuron autophagy and degeneration. Hum Mol Genet, 2001. 10(12): p. 1243-54.

28. Kegel, K.B., M. Kim, E. Sapp, C. McIntyre, J.G. Castano, N. Aronin, and M. DiFiglia, Huntingtin expression stimulates endosomal-lysosomal activity, endosome tubulation, and autophagy. J Neurosci, 2000. 20(19): p. 7268-78.

29. Martinez-Vicente, M., Z. Talloczy, E. Wong, G. Tang, H. Koga, S. Kaushik, R. de Vries, E. Arias, S. Harris, D. Sulzer, and A.M. Cuervo, Cargo recognition failure is responsible for inefficient autophagy in Huntington's disease. Nat Neurosci, 2010. 13(5): p. 567-76. 
30. Rui, Y.N., Z. Xu, B. Patel, Z. Chen, D. Chen, A. Tito, G. David, Y. Sun, E.F. Stimming, H.J. Bellen, A.M. Cuervo, and S. Zhang, Huntingtin functions as a scaffold for selective macroautophagy. Nat Cell Biol, 2015. 17(3): p. 262-75.

31. Ochaba, J., T. Lukacsovich, G. Csikos, S. Zheng, J. Margulis, L. Salazar, K. Mao, A.L. Lau, S.Y. Yeung, S. Humbert, F. Saudou, D.J. Klionsky, S. Finkbeiner, S.O. Zeitlin, J.L. Marsh, D.E. Housman, L.M. Thompson, and J.S. Steffan, Potential function for the Huntingtin protein as a scaffold for selective autophagy. Proc Natl Acad Sci U S A, 2014. 111(47): p. 16889-94.

32. Croce, K.R. and A. Yamamoto, A role for autophagy in Huntington's disease. Neurobiol Dis, 2019. 122: p. 16-22.

33. Ravikumar, B. and D.C. Rubinsztein, Role of autophagy in the clearance of mutant huntingtin: a step towards therapy? Mol Aspects Med, 2006. 27(5-6): p. 520-7.

34. Rubinsztein, D.C., The roles of intracellular protein-degradation pathways in neurodegeneration. Nature, 2006. 443(7113): p. 780-6.

35. Sarkar, S., E.O. Perlstein, S. Imarisio, S. Pineau, A. Cordenier, R.L. Maglathlin, J.A. Webster, T.A. Lewis, C.J. O'Kane, S.L. Schreiber, and D.C. Rubinsztein, Small molecules enhance autophagy and reduce toxicity in Huntington's disease models. Nat Chem Biol, 2007. 3(6): p. 331-8.

36. Singer, E., C. Walter, D. Fabbro, D. Rageot, F. Beaufils, M.P. Wymann, N. Rischert, O. Riess, P. Hillmann, and H.P. Nguyen, Brain-penetrant PQR620 mTOR and PQR530 PI3K/mTOR inhibitor reduce huntingtin levels in cell models of HD. Neuropharmacology, 2020. 162: p. 107812.

37. Martinez-Vicente, M., Novel Therapeutic Approach to Induce Autophagy in a Drosophila Model for Huntington's Disease. Cells, 2020. 9(2).

38. Ravikumar, B., S. Imarisio, S. Sarkar, C.J. O'Kane, and D.C. Rubinsztein, Rab5 modulates aggregation and toxicity of mutant huntingtin through macroautophagy in cell and fly models of Huntington disease. J Cell Sci, 2008. 121(Pt 10): p. 1649-60.

39. Bauer, P.O. and N. Nukina, Enhanced degradation of mutant huntingtin by rho kinase inhibition is mediated through activation of proteasome and macroautophagy. Autophagy, 2009. 5(5): p. 747-8.

40. Tsvetkov, A.S., J. Miller, M. Arrasate, J.S. Wong, M.A. Pleiss, and S. Finkbeiner, $A$ small-molecule scaffold induces autophagy in primary neurons and protects against toxicity in a Huntington disease model. Proc Natl Acad Sci U S A, 2010. 107(39): p. 16982-7.

41. Roscic, A., B. Baldo, C. Crochemore, D. Marcellin, and P. Paganetti, Induction of autophagy with catalytic $m$ TOR inhibitors reduces huntingtin aggregates in a neuronal cell model. J Neurochem, 2011. 119(2): p. 398-407.

42. Sarkar, S., B. Ravikumar, R.A. Floto, and D.C. Rubinsztein, Rapamycin and mTORindependent autophagy inducers ameliorate toxicity of polyglutamine-expanded huntingtin and related proteinopathies. Cell Death Differ, 2009. 16(1): p. 46-56.

43. Aron, R., P. Pellegrini, E.W. Green, D.C. Maddison, K. Opoku-Nsiah, A.O. Oliveira, J.S. Wong, A.C. Daub, F. Giorgini, P. Muchowski, and S. Finkbeiner, Deubiquitinase Usp12 functions noncatalytically to induce autophagy and confer neuroprotection in models of Huntington's disease. Nat Commun, 2018. 9(1): p. 3191. 
44. Ravikumar, B., A. Acevedo-Arozena, S. Imarisio, Z. Berger, C. Vacher, C.J. O'Kane, S.D. Brown, and D.C. Rubinsztein, Dynein mutations impair autophagic clearance of aggregate-prone proteins. Nat Genet, 2005. 37(7): p. 771-6.

45. Iwata, A., J.C. Christianson, M. Bucci, L.M. Ellerby, N. Nukina, L.S. Forno, and R.R. Kopito, Increased susceptibility of cytoplasmic over nuclear polyglutamine aggregates to autophagic degradation. Proc Natl Acad Sci U S A, 2005. 102(37): p. 13135-40.

46. Bauer, P.O., A. Goswami, H.K. Wong, M. Okuno, M. Kurosawa, M. Yamada, H. Miyazaki, G. Matsumoto, Y. Kino, Y. Nagai, and N. Nukina, Harnessing chaperonemediated autophagy for the selective degradation of mutant huntingtin protein. Nat Biotechnol, 2010. 28(3): p. 256-63.

47. Shin, B.H., Y. Lim, H.J. Oh, S.M. Park, S.K. Lee, J. Ahnn, D.H. Kim, W.K. Song, T.H. Kwak, and W.J. Park, Pharmacological activation of Sirt1 ameliorates polyglutamineinduced toxicity through the regulation of autophagy. PLoS One, 2013. 8(6): p. e64953.

48. Lu, K., I. Psakhye, and S. Jentsch, Autophagic clearance of polyQ proteins mediated by ubiquitin-Atg8 adaptors of the conserved CUET protein family. Cell, 2014. 158(3): p. 549-63.

49. Jiang, W., W. Wei, M.A. Gaertig, S. Li, and X.J. Li, Therapeutic Effect of Berberine on Huntington's Disease Transgenic Mouse Model. PLoS One, 2015. 10(7): p. e0134142.

50. Moruno Manchon, J.F., N.E. Uzor, Y. Dabaghian, E.E. Furr-Stimming, S. Finkbeiner, and A.S. Tsvetkov, Cytoplasmic sphingosine-1-phosphate pathway modulates neuronal autophagy. Sci Rep, 2015. 5: p. 15213.

51. Abd-Elrahman, K.S., A. Hamilton, S.R. Hutchinson, F. Liu, R.C. Russell, and S.S.G. Ferguson, $m$ GluR5 antagonism increases autophagy and prevents disease progression in the zQ175 mouse model of Huntington's disease. Sci Signal, 2017. 10(510).

52. Ochaba, J., G. Fote, M. Kachemov, S. Thein, S.Y. Yeung, A.L. Lau, S. Hernandez, R.G. Lim, M. Casale, M.J. Neel, E.S. Monuki, J. Reidling, D.E. Housman, L.M. Thompson, and J.S. Steffan, IKKbeta slows Huntington's disease progression in R6/1 mice. Proc Natl Acad Sci U S A, 2019. 116(22): p. 10952-10961.

53. Li, Z., C. Wang, Z. Wang, C. Zhu, J. Li, T. Sha, L. Ma, C. Gao, Y. Yang, Y. Sun, J. Wang, X. Sun, C. Lu, M. Difiglia, Y. Mei, C. Ding, S. Luo, Y. Dang, Y. Ding, Y. Fei, and B. Lu, Allele-selective lowering of mutant HTT protein by HTT-LC3 linker compounds. Nature, 2019. 575(7781): p. 203-209.

54. Vernizzi, L., C. Paiardi, G. Licata, T. Vitali, S. Santarelli, M. Raneli, V. Manelli, M. Rizzetto, M. Gioria, M.E. Pasini, D. Grifoni, M.A. Vanoni, C. Gellera, F. Taroni, and P. Bellosta, Glutamine Synthetase 1 Increases Autophagy Lysosomal Degradation of Mutant Huntingtin Aggregates in Neurons, Ameliorating Motility in a Drosophila Model for Huntington's Disease. Cells, 2020. 9(1).

55. Nobrega, C., A. Conceicao, R.G. Costa, R. Koppenol, R.L. Sequeira, R. Nunes, S. Carmo-Silva, A. Marcelo, C.A. Matos, S. Betuing, J. Caboche, N. Cartier, and S. Alves, The cholesterol 24-hydroxylase activates autophagy and decreases mutant huntingtin build-up in a neuroblastoma culture model of Huntington's disease. BMC Res Notes, 2020. 13(1): p. 210.

56. Margulis, J. and S. Finkbeiner, Proteostasis in striatal cells and selective neurodegeneration in Huntington's disease. Front Cell Neurosci, 2014. 8: p. 218.

57. Celen, A.B. and U. Sahin, Sumoylation on its 25th anniversary: mechanisms, pathology, and emerging concepts. FEBS J, 2020. 
58. Anderson, D.B., C.A. Zanella, J.M. Henley, and H. Cimarosti, Sumoylation: Implications for Neurodegenerative Diseases. Adv Exp Med Biol, 2017. 963: p. 261-281.

59. Wilkinson, K.A., Y. Nakamura, and J.M. Henley, Targets and consequences of protein SUMOylation in neurons. Brain Res Rev, 2010. 64(1): p. 195-212.

60. Dorval, V. and P.E. Fraser, SUMO on the road to neurodegeneration. Biochim Biophys Acta, 2007. 1773(6): p. 694-706.

61. Princz, A. and N. Tavernarakis, SUMOylation in Neurodegenerative Diseases. Gerontology, 2020. 66(2): p. 122-130.

62. Martins, W.C., C.I. Tasca, and H. Cimarosti, Battling Alzheimer's Disease: Targeting SUMOylation-Mediated Pathways. Neurochem Res, 2016. 41(3): p. 568-78.

63. Wen, D., J. Wu, L. Wang, and Z. Fu, SUMOylation Promotes Nuclear Import and Stabilization of Polo-like Kinase 1 to Support Its Mitotic Function. Cell Rep, 2017. 21(8): p. 2147-2159.

64. Iyer, R.S., L. Chatham, R. Sleigh, and D.W. Meek, A functional SUMO-motif in the active site of PIM1 promotes its degradation via RNF4, and stimulates protein kinase activity. Sci Rep, 2017. 7(1): p. 3598.

65. Gonzalez-Santamaria, J., M. Campagna, A. Ortega-Molina, L. Marcos-Villar, C.F. de la Cruz-Herrera, D. Gonzalez, P. Gallego, F. Lopitz-Otsoa, M. Esteban, M.S. Rodriguez, M. Serrano, and C. Rivas, Regulation of the tumor suppressor PTEN by SUMO. Cell Death Dis, 2012. 3: p. e393.

66. Huang, J., J. Yan, J. Zhang, S. Zhu, Y. Wang, T. Shi, C. Zhu, C. Chen, X. Liu, J. Cheng, T. Mustelin, G.S. Feng, G. Chen, and J. Yu, SUMO1 modification of PTEN regulates tumorigenesis by controlling its association with the plasma membrane. Nat Commun, 2012. 3: p. 911.

67. Li, R., J. Wei, C. Jiang, D. Liu, L. Deng, K. Zhang, and P. Wang, Akt SUMOylation regulates cell proliferation and tumorigenesis. Cancer Res, 2013. 73(18): p. 5742-53.

68. de la Cruz-Herrera, C.F., M. Campagna, V. Lang, J. del Carmen Gonzalez-Santamaria, L. Marcos-Villar, M.S. Rodriguez, A. Vidal, M. Collado, and C. Rivas, SUMOylation regulates AKT1 activity. Oncogene, 2015. 34(11): p. 1442-50.

69. Rubio, T., S. Vernia, and P. Sanz, Sumoylation of AMPKbeta2 subunit enhances AMPactivated protein kinase activity. Mol Biol Cell, 2013. 24(11): p. 1801-11, S1-4.

70. Yan, Y., S. Ollila, I.P.L. Wong, T. Vallenius, J.J. Palvimo, K. Vaahtomeri, and T.P. Makela, SUMOylation of AMPKalphal by PIAS4 specifically regulates mTORC1 signalling. Nat Commun, 2015. 6: p. 8979.

71. Saul, V.V., R. Niedenthal, A. Pich, F. Weber, and M.L. Schmitz, SUMO modification of TBK1 at the adaptor-binding C-terminal coiled-coil domain contributes to its antiviral activity. Biochim Biophys Acta, 2015. 1853(1): p. 136-43.

72. Rabellino, A., C. Andreani, and P.P. Scaglioni, The Role of PIAS SUMO E3-Ligases in Cancer. Cancer Res, 2017. 77(7): p. 1542-1547.

73. Flotho, A. and F. Melchior, Sumoylation: a regulatory protein modification in health and disease. Annu Rev Biochem, 2013. 82: p. 357-85.

74. Rao, H.B., H. Qiao, S.K. Bhatt, L.R. Bailey, H.D. Tran, S.L. Bourne, W. Qiu, A. Deshpande, A.N. Sharma, C.J. Beebout, R.J. Pezza, and N. Hunter, A SUMO-ubiquitin relay recruits proteasomes to chromosome axes to regulate meiotic recombination. Science, 2017. 355(6323): p. 403-407. 
75. Yau, T.Y., O. Molina, and A.J. Courey, SUMOylation in development and neurodegeneration. Development, 2020. 147(6).

76. Yang, Y., W. Fiskus, B. Yong, P. Atadja, Y. Takahashi, T.K. Pandita, H.G. Wang, and K.N. Bhalla, Acetylated hsp70 and KAP1-mediated Vps34 SUMOylation is required for autophagosome creation in autophagy. Proc Natl Acad Sci U S A, 2013. 110(17): p. 6841-6.

77. Popelka, H. and D.J. Klionsky, Post-translationally-modified structures in the autophagy machinery: an integrative perspective. FEBS J, 2015. 282(18): p. 3474-88.

78. Zhang, F.P., L. Mikkonen, J. Toppari, J.J. Palvimo, I. Thesleff, and O.A. Janne, Sumo-1 function is dispensable in normal mouse development. Mol Cell Biol, 2008. 28(17): p. 5381-90.

79. Evdokimov, E., P. Sharma, S.J. Lockett, M. Lualdi, and M.R. Kuehn, Loss of SUMO1 in mice affects RanGAP1 localization and formation of PML nuclear bodies, but is not lethal as it can be compensated by SUMO2 or SUMO3. J Cell Sci, 2008. 121(Pt 24): p. 4106-13.

80. Wang, L., C. Wansleeben, S. Zhao, P. Miao, W. Paschen, and W. Yang, SUMO2 is essential while SUMO3 is dispensable for mouse embryonic development. EMBO Rep, 2014. 15(8): p. 878-85.

81. Subramaniam, S., R.G. Mealer, K.M. Sixt, R.K. Barrow, A. Usiello, and S.H. Snyder, Rhes, a physiologic regulator of sumoylation, enhances cross-sumoylation between the basic sumoylation enzymes E1 and Ubc9. J Biol Chem, 2010. 285(27): p. 20428-32.

82. Oscar Rivera, M.S., Neelam Shahani, Uri Nimrod Ramírez-Jarquín, Gogce Crynen, Pabalu Karunadharma, Francis McManus, Thibault Pierre, Srinivasa Subramaniam, Rhes, a Striatal Enriched Protein, Regulates Post-Translational Small-Ubiquitin-like-Modifier (SUMO) Modification of Nuclear Proteins and Alters Gene Expression. BioRxiv, 2020.

83. O'Rourke, J.G., J.R. Gareau, J. Ochaba, W. Song, T. Rasko, D. Reverter, J. Lee, A.M. Monteys, J. Pallos, L. Mee, M. Vashishtha, B.L. Apostol, T.P. Nicholson, K. Illes, Y.Z. Zhu, M. Dasso, G.P. Bates, M. Difiglia, B. Davidson, E.E. Wanker, J.L. Marsh, C.D. Lima, J.S. Steffan, and L.M. Thompson, SUMO-2 and PIAS1 modulate insoluble mutant huntingtin protein accumulation. Cell Rep, 2013. 4(2): p. 362-75.

84. Steffan, J.S., N. Agrawal, J. Pallos, E. Rockabrand, L.C. Trotman, N. Slepko, K. Illes, T. Lukacsovich, Y.Z. Zhu, E. Cattaneo, P.P. Pandolfi, L.M. Thompson, and J.L. Marsh, SUMO modification of Huntingtin and Huntington's disease pathology. Science, 2004. 304(5667): p. 100-4.

85. Sharma, M. and S. Subramaniam, Rhes travels from cell to cell and transports Huntington disease protein via TNT-like protrusion. J Cell Biol, 2019. 218(6): p. 19721993.

86. Subramaniam, S., K.M. Sixt, R. Barrow, and S.H. Snyder, Rhes, a striatal specific protein, mediates mutant-huntingtin cytotoxicity. Science, 2009. 324(5932): p. 1327-30.

87. Okamoto, S., M.A. Pouladi, M. Talantova, D. Yao, P. Xia, D.E. Ehrnhoefer, R. Zaidi, A. Clemente, M. Kaul, R.K. Graham, D. Zhang, H.S. Vincent Chen, G. Tong, M.R. Hayden, and S.A. Lipton, Balance between synaptic versus extrasynaptic NMDA receptor activity influences inclusions and neurotoxicity of mutant huntingtin. Nat Med, 2009. 15(12): p. 1407-13. 
88. Seredenina, T., O. Gokce, and R. Luthi-Carter, Decreased striatal RGS2 expression is neuroprotective in Huntington's disease (HD) and exemplifies a compensatory aspect of HD-induced gene regulation. PLoS One, 2011. 6(7): p. e22231.

89. Sbodio, J.I., B.D. Paul, C.E. Machamer, and S.H. Snyder, Golgi protein ACBD3 mediates neurotoxicity associated with Huntington's disease. Cell Rep, 2013. 4(5): p. 890-7.

90. Lu, B. and J. Palacino, A novel human embryonic stem cell-derived Huntington's disease neuronal model exhibits mutant huntingtin (mHTT) aggregates and soluble mHTTdependent neurodegeneration. FASEB J, 2013. 27(5): p. 1820-9.

91. Argenti, M., THE ROLE OF MITOCHONDRIAL DYSFUNCTION IN HUNTINGTON'S DISEASE PATHOGENESIS AND ITS RELATION WITH STRIATAL RHES PROTEIN. Ph.D Thesis, Università degli Studi di Padova, Padova PD, Italy, 2014.

92. Swarnkar, S., Y. Chen, W.M. Pryor, N. Shahani, D.T. Page, and S. Subramaniam, Ectopic expression of the striatal-enriched GTPase Rhes elicits cerebellar degeneration and an ataxia phenotype in Huntington's disease. Neurobiol Dis, 2015. 82: p. 66-77.

93. Baiamonte, B.A., F.A. Lee, S.T. Brewer, D. Spano, and G.J. LaHoste, Attenuation of Rhes activity significantly delays the appearance of behavioral symptoms in a mouse model of Huntington's disease. PLoS One, 2013. 8(1): p. e53606.

94. Liu, Q., S. Cheng, H. Yang, L. Zhu, Y. Pan, L. Jing, B. Tang, S. Li, and X.J. Li, Loss of Hapl selectively promotes striatal degeneration in Huntington disease mice. Proc Natl Acad Sci U S A, 2020. 117(33): p. 20265-20273.

95. Hernandez, I., G. Luna, J.N. Rauch, S.A. Reis, M. Giroux, C.M. Karch, D. Boctor, Y.E. Sibih, N.J. Storm, A. Diaz, S. Kaushik, C. Zekanowski, A.A. Kang, C.R. Hinman, V. Cerovac, E. Guzman, H. Zhou, S.J. Haggarty, A.M. Goate, S.K. Fisher, A.M. Cuervo, and K.S. Kosik, A farnesyltransferase inhibitor activates lysosomes and reduces tau pathology in mice with tauopathy. Sci Transl Med, 2019. 11(485).

96. Alexander J. Ehrenberg, K.L., Israel Hernandez, Caroline Lew, William W. Seeley, Salvatore Spina, Bruce Miller, Helmut Heinsen, Martin Kampmann, Kenneth S. Kosik, Lea T. Grinberg, Mislocalization and clearance of neuronal Rhes as a novel hallmark of tauopathies. medRxiv, 2020.

97. Southwell, A.L., A. Smith-Dijak, C. Kay, M. Sepers, E.B. Villanueva, M.P. Parsons, Y. Xie, L. Anderson, B. Felczak, S. Waltl, S. Ko, D. Cheung, L. Dal Cengio, R. Slama, E. Petoukhov, L.A. Raymond, and M.R. Hayden, An enhanced Q175 knock-in mouse model of Huntington disease with higher mutant huntingtin levels and accelerated disease phenotypes. Hum Mol Genet, 2016. 25(17): p. 3654-3675.

98. Menalled, L.B., A.E. Kudwa, S. Miller, J. Fitzpatrick, J. Watson-Johnson, N. Keating, M. Ruiz, R. Mushlin, W. Alosio, K. McConnell, D. Connor, C. Murphy, S. Oakeshott, M. Kwan, J. Beltran, A. Ghavami, D. Brunner, L.C. Park, S. Ramboz, and D. Howland, Comprehensive behavioral and molecular characterization of a new knock-in mouse model of Huntington's disease: zQ175. PLoS One, 2012. 7(12): p. e49838.

99. Heikkinen, T., K. Lehtimaki, N. Vartiainen, J. Puolivali, S.J. Hendricks, J.R. Glaser, A. Bradaia, K. Wadel, C. Touller, O. Kontkanen, J.M. Yrjanheikki, B. Buisson, D. Howland, V. Beaumont, I. Munoz-Sanjuan, and L.C. Park, Characterization of neurophysiological and behavioral changes, MRI brain volumetry and $1 H$ MRS in zQ175 knock-in mouse model of Huntington's disease. PLoS One, 2012. 7(12): p. e50717. 
100. Pryor, W.M., M. Biagioli, N. Shahani, S. Swarnkar, W.C. Huang, D.T. Page, M.E. MacDonald, and S. Subramaniam, Huntingtin promotes mTORC1 signaling in the pathogenesis of Huntington's disease. Sci Signal, 2014. 7(349): p. ra103.

101. Luthi-Carter, R., A.D. Strand, S.A. Hanson, C. Kooperberg, G. Schilling, A.R. La Spada, D.E. Merry, A.B. Young, C.A. Ross, D.R. Borchelt, and J.M. Olson, Polyglutamine and transcription: gene expression changes shared by DRPLA and Huntington's disease mouse models reveal context-independent effects. Hum Mol Genet, 2002. 11(17): p. 1927-37.

102. McColgan, P., S. Gregory, K.K. Seunarine, A. Razi, M. Papoutsi, E. Johnson, A. Durr, R.A.C. Roos, B.R. Leavitt, P. Holmans, R.I. Scahill, C.A. Clark, G. Rees, S.J. Tabrizi, and H.D.I. Track-On, Brain Regions Showing White Matter Loss in Huntington's Disease Are Enriched for Synaptic and Metabolic Genes. Biol Psychiatry, 2018. 83(5): p. 456465.

103. Cha, J.H., Transcriptional signatures in Huntington's disease. Prog Neurobiol, 2007. 83(4): p. 228-48.

104. Geiss-Friedlander, R. and F. Melchior, Concepts in sumoylation: a decade on. Nat Rev Mol Cell Biol, 2007. 8(12): p. 947-56.

105. Liu, H.W., J. Zhang, G.F. Heine, M. Arora, H. Gulcin Ozer, R. Onti-Srinivasan, K. Huang, and J.D. Parvin, Chromatin modification by SUMO-1 stimulates the promoters of translation machinery genes. Nucleic Acids Res, 2012. 40(20): p. 10172-86.

106. Rosonina, E., A. Akhter, Y. Dou, J. Babu, and V.S. Sri Theivakadadcham, Regulation of transcription factors by sumoylation. Transcription, 2017. 8(4): p. 220-231.

107. Langfelder, P., J.P. Cantle, D. Chatzopoulou, N. Wang, F. Gao, I. Al-Ramahi, X.H. Lu, E.M. Ramos, K. El-Zein, Y. Zhao, S. Deverasetty, A. Tebbe, C. Schaab, D.J. Lavery, D. Howland, S. Kwak, J. Botas, J.S. Aaronson, J. Rosinski, G. Coppola, S. Horvath, and $\mathrm{X} . \mathrm{W}$. Yang, Integrated genomics and proteomics define huntingtin CAG lengthdependent networks in mice. Nat Neurosci, 2016. 19(4): p. 623-33.

108. Sanchis, A., M.A. Garcia-Gimeno, A.J. Canada-Martinez, M.D. Sequedo, J.M. Millan, P. Sanz, and R.P. Vazquez-Manrique, Metformin treatment reduces motor and neuropsychiatric phenotypes in the zQ175 mouse model of Huntington disease. Exp Mol Med, 2019. 51(6): p. 1-16.

109. Diaz-Castro, B., M.R. Gangwani, X. Yu, G. Coppola, and B.S. Khakh, Astrocyte molecular signatures in Huntington's disease. Sci Transl Med, 2019. 11(514).

110. Ivkovic, S. and M.E. Ehrlich, Expression of the striatal DARPP-32/ARPP-21 phenotype in GABAergic neurons requires neurotrophins in vivo and in vitro. J Neurosci, 1999. 19(13): p. 5409-19.

111. Arlotta, P., B.J. Molyneaux, D. Jabaudon, Y. Yoshida, and J.D. Macklis, Ctip2 controls the differentiation of medium spiny neurons and the establishment of the cellular architecture of the striatum. J Neurosci, 2008. 28(3): p. 622-32.

112. Guo, L., B.I. Giasson, A. Glavis-Bloom, M.D. Brewer, J. Shorter, A.D. Gitler, and X. Yang, A cellular system that degrades misfolded proteins and protects against neurodegeneration. Mol Cell, 2014. 55(1): p. 15-30.

113. Vijayakumaran, S., M.B. Wong, H. Antony, and D.L. Pountney, Direct and/or Indirect Roles for SUMO in Modulating Alpha-Synuclein Toxicity. Biomolecules, 2015. 5(3): p. 1697-716. 
114. Reif, A., A. Chiki, J. Ricci, and H.A. Lashuel, Generation of Native, Untagged Huntingtin Exon1 Monomer and Fibrils Using a SUMO Fusion Strategy. J Vis Exp, 2018(136).

115. Zhu, G., D.S. Harischandra, S. Ghaisas, P. Zhang, W. Prall, L. Huang, C. Maghames, L. Guo, E. Luna, K.L. Mack, M.P. Torrente, K.C. Luk, J. Shorter, and X. Yang, TRIM11 Prevents and Reverses Protein Aggregation and Rescues a Mouse Model of Parkinson's Disease. Cell Rep, 2020. 33(9): p. 108418.

116. Gutekunst, C.A., S.H. Li, H. Yi, J.S. Mulroy, S. Kuemmerle, R. Jones, D. Rye, R.J. Ferrante, S.M. Hersch, and X.J. Li, Nuclear and neuropil aggregates in Huntington's disease: relationship to neuropathology. J Neurosci, 1999. 19(7): p. 2522-34.

117. Bayram-Weston, Z., L. Jones, S.B. Dunnett, and S.P. Brooks, Comparison of mHTT Antibodies in Huntington's Disease Mouse Models Reveal Specific Binding Profiles and Steady-State Ubiquitin Levels with Disease Development. PLoS One, 2016. 11(5): p. e0155834.

118. Macdonald, D., M.A. Tessari, I. Boogaard, M. Smith, K. Pulli, A. Szynol, F. Albertus, M.B. Lamers, S. Dijkstra, D. Kordt, W. Reindl, F. Herrmann, G. McAllister, D.F. Fischer, and I. Munoz-Sanjuan, Quantification assays for total and polyglutamineexpanded huntingtin proteins. PLoS One, 2014. 9(5): p. e96854.

119. Nucifora, L.G., K.A. Burke, X. Feng, N. Arbez, S. Zhu, J. Miller, G. Yang, T. Ratovitski, M. Delannoy, P.J. Muchowski, S. Finkbeiner, J. Legleiter, C.A. Ross, and M.A. Poirier, Identification of novel potentially toxic oligomers formed in vitro from mammalianderived expanded huntingtin exon-1 protein. J Biol Chem, 2012. 287(19): p. 16017-28.

120. Sun, X., Y. Fu, Y. Pan, and B. Lu, Conformation-dependent recognition of mutant HTT (huntingtin) proteins by selective autophagy. Autophagy, 2017. 13(12): p. 2111-2112.

121. Muinao, T., M. Pal, and H.P.D. Boruah, Cytosolic and Transmembrane Protein Extraction Methods of Breast and Ovarian Cancer Cells: A Comparative Study. J Biomol Tech, 2018. 29(3): p. 71-78.

122. Cordwell, S.J., Sequential extraction of proteins by chemical reagents. Methods Mol Biol, 2008. 424: p. 139-46.

123. Reindl, W., B. Baldo, J. Schulz, I. Janack, I. Lindner, M. Kleinschmidt, Y. Sedaghat, C. Thiede, K. Tillack, C. Schmidt, I. Cardaun, T. Schwagarus, F. Herrmann, M. Hotze, G.F. Osborne, S. Herrmann, A. Weiss, C. Zerbinatti, G.P. Bates, J. Bard, I. Munoz-Sanjuan, and D. Macdonald, Meso scale discovery-based assays for the detection of aggregated huntingtin. PLoS One, 2019. 14(3): p. e0213521.

124. Fodale, V., R. Pintauro, M. Daldin, R. Altobelli, M.C. Spiezia, M. Bisbocci, D. Macdonald, and A. Bresciani, Analysis of mutant and total huntingtin expression in Huntington's disease murine models. Sci Rep, 2020. 10(1): p. 22137.

125. Johansen, T. and T. Lamark, Selective autophagy mediated by autophagic adapter proteins. Autophagy, 2011. 7(3): p. 279-96.

126. Kurosawa, M., G. Matsumoto, Y. Kino, M. Okuno, M. Kurosawa-Yamada, C. Washizu, H. Taniguchi, K. Nakaso, T. Yanagawa, E. Warabi, T. Shimogori, T. Sakurai, N. Hattori, and N. Nukina, Depletion of p62 reduces nuclear inclusions and paradoxically ameliorates disease phenotypes in Huntington's model mice. Hum Mol Genet, 2015. 24(4): p. 1092-105. 
127. Sha, Z., H.M. Schnell, K. Ruoff, and A. Goldberg, Rapid induction of p62 and GABARAPL1 upon proteasome inhibition promotes survival before autophagy activation. J Cell Biol, 2018. 217(5): p. 1757-1776.

128. Nagaoka, U., K. Kim, N.R. Jana, H. Doi, M. Maruyama, K. Mitsui, F. Oyama, and N. Nukina, Increased expression of 62 in expanded polyglutamine-expressing cells and its association with polyglutamine inclusions. J Neurochem, 2004. 91(1): p. 57-68.

129. Bjorkoy, G., T. Lamark, A. Brech, H. Outzen, M. Perander, A. Overvatn, H. Stenmark, and T. Johansen, p62/SQSTM1 forms protein aggregates degraded by autophagy and has a protective effect on huntingtin-induced cell death. J Cell Biol, 2005. 171(4): p. 603-14.

130. Heng, M.Y., D.K. Duong, R.L. Albin, S.J. Tallaksen-Greene, J.M. Hunter, M.J. Lesort, A. Osmand, H.L. Paulson, and P.J. Detloff, Early autophagic response in a novel knockin model of Huntington disease. Hum Mol Genet, 2010. 19(19): p. 3702-20.

131. Dunn, K.W., M.M. Kamocka, and J.H. McDonald, A practical guide to evaluating colocalization in biological microscopy. Am J Physiol Cell Physiol, 2011. 300(4): p. C723-42.

132. Adler, J. and I. Parmryd, Quantifying colocalization: thresholding, void voxels and the H(coef). PLoS One, 2014. 9(11): p. e111983.

133. Menzies, F.M., A. Fleming, A. Caricasole, C.F. Bento, S.P. Andrews, A. Ashkenazi, J. Fullgrabe, A. Jackson, M. Jimenez Sanchez, C. Karabiyik, F. Licitra, A. Lopez Ramirez, M. Pavel, C. Puri, M. Renna, T. Ricketts, L. Schlotawa, M. Vicinanza, H. Won, Y. Zhu, J. Skidmore, and D.C. Rubinsztein, Autophagy and Neurodegeneration: Pathogenic Mechanisms and Therapeutic Opportunities. Neuron, 2017. 93(5): p. 1015-1034.

134. Martin, D.D., S. Ladha, D.E. Ehrnhoefer, and M.R. Hayden, Autophagy in Huntington disease and huntingtin in autophagy. Trends Neurosci, 2015. 38(1): p. 26-35.

135. Trettel, F., D. Rigamonti, P. Hilditch-Maguire, V.C. Wheeler, A.H. Sharp, F. Persichetti, E. Cattaneo, and M.E. MacDonald, Dominant phenotypes produced by the HD mutation in STHdh(Q111) striatal cells. Hum Mol Genet, 2000. 9(19): p. 2799-809.

136. Fukuda, I., A. Ito, G. Hirai, S. Nishimura, H. Kawasaki, H. Saitoh, K. Kimura, M. Sodeoka, and M. Yoshida, Ginkgolic acid inhibits protein SUMOylation by blocking formation of the E1-SUMO intermediate. Chem Biol, 2009. 16(2): p. 133-40.

137. Xiao, Y., B. Lucas, E. Molcho, T. Schiff, and M. Vigodner, Inhibition of CDK1 activity by sumoylation. Biochem Biophys Res Commun, 2016. 478(2): p. 919-23.

138. Qiu, F., C. Dong, Y. Liu, X. Shao, D. Huang, Y. Han, B. Wang, Y. Liu, R. Huo, P. Paulo, Z.R. Zhang, D. Zhao, and W.F. Chu, Pharmacological inhibition of SUMO-1 with ginkgolic acid alleviates cardiac fibrosis induced by myocardial infarction in mice. Toxicol Appl Pharmacol, 2018. 345: p. 1-9.

139. Liu, K., X. Wang, D. Li, D. Xu, D. Li, Z. Lv, D. Zhao, W.F. Chu, and X.F. Wang, Ginkgolic Acid, a SUMO-1 Inhibitor, Inhibits the Progression of Oral Squamous Cell Carcinoma by Alleviating SUMOylation of SMAD4. Mol Ther Oncolytics, 2020. 16: p. 86-99.

140. Brackett, C.M., A. Garcia-Casas, S. Castillo-Lluva, and B.S.J. Blagg, Synthesis and Evaluation of Ginkgolic Acid Derivatives as SUMOylation Inhibitors. ACS Med Chem Lett, 2020. 11(11): p. 2221-2226.

141. Ochaba, J., A.M. Monteys, J.G. O'Rourke, J.C. Reidling, J.S. Steffan, B.L. Davidson, and L.M. Thompson, PIAS1 Regulates Mutant Huntingtin Accumulation and Huntington's Disease-Associated Phenotypes In Vivo. Neuron, 2016. 90(3): p. 507-20. 
142. Arrasate, M., S. Mitra, E.S. Schweitzer, M.R. Segal, and S. Finkbeiner, Inclusion body formation reduces levels of mutant huntingtin and the risk of neuronal death. Nature, 2004. 431(7010): p. 805-10.

143. Saudou, F., S. Finkbeiner, D. Devys, and M.E. Greenberg, Huntingtin acts in the nucleus to induce apoptosis but death does not correlate with the formation of intranuclear inclusions. Cell, 1998. 95(1): p. 55-66.

144. Todd, T.W. and J. Lim, Aggregation formation in the polyglutamine diseases: protection at a cost? Mol Cells, 2013. 36(3): p. 185-94.

145. Yao, Y., H. Li, X. Da, Z. He, B. Tang, Y. Li, C. Hu, C. Xu, Q. Chen, and Q.K. Wang, SUMOylation of Vps34 by SUMO1 promotes phenotypic switching of vascular smooth muscle cells by activating autophagy in pulmonary arterial hypertension. Pulm Pharmacol Ther, 2019. 55: p. 38-49.

146. Gupta, M.K., P.M. McLendon, J. Gulick, J. James, K. Khalili, and J. Robbins, UBC9Mediated Sumoylation Favorably Impacts Cardiac Function in Compromised Hearts. Circ Res, 2016. 118(12): p. 1894-905.

147. Liu, M., T. Zeng, X. Zhang, C. Liu, Z. Wu, L. Yao, C. Xie, H. Xia, Q. Lin, L. Xie, D. Zhou, X. Deng, H.L. Chan, T.J. Zhao, and H.R. Wang, ATR/Chk1 signaling induces autophagy through sumoylated RhoB-mediated lysosomal translocation of TSC2 after DNA damage. Nat Commun, 2018. 9(1): p. 4139.

148. Liu, K., C. Guo, Y. Lao, J. Yang, F. Chen, Y. Zhao, Y. Yang, J. Yang, and J. Yi, A finetuning mechanism underlying self-control for autophagy: deSUMOylation of BECN1 by SENP3. Autophagy, 2020. 16(6): p. 975-990.

149. Lorente, M., A. Garcia-Casas, N. Salvador, A. Martinez-Lopez, E. Gabicagogeascoa, G. Velasco, L. Lopez-Palomar, and S. Castillo-Lluva, Inhibiting SUMO1-mediated SUMOylation induces autophagy-mediated cancer cell death and reduces tumour cell invasion via RAC1. J Cell Sci, 2019. 132(20).

150. Kim, Y.C. and K.L. Guan, $m$ TOR: a pharmacologic target for autophagy regulation. J Clin Invest, 2015. 125(1): p. 25-32.

151. Mealer, R.G., A.J. Murray, N. Shahani, S. Subramaniam, and S.H. Snyder, Rhes, a striatal-selective protein implicated in Huntington disease, binds beclin-1 and activates autophagy. J Biol Chem, 2014. 289(6): p. 3547-54.

152. Soares, T.R., S.D. Reis, B.R. Pinho, M.R. Duchen, and J.M.A. Oliveira, Targeting the proteostasis network in Huntington's disease. Ageing Res Rev, 2019. 49: p. 92-103.

153. Zhao, T., Y. Hong, S. Li, and X.J. Li, Compartment-Dependent Degradation of Mutant Huntingtin Accounts for Its Preferential Accumulation in Neuronal Processes. J Neurosci, 2016. 36(32): p. 8317-28.

154. Vodicka, P., K. Chase, M. Iuliano, A. Tousley, D.T. Valentine, E. Sapp, K.B. KegelGleason, M. Sena-Esteves, N. Aronin, and M. DiFiglia, Autophagy Activation by Transcription Factor EB (TFEB) in Striatum of HDQ175/Q7 Mice. J Huntingtons Dis, 2016. 5(3): p. 249-260.

155. Zhao, J., B. Zhai, S.P. Gygi, and A.L. Goldberg, mTOR inhibition activates overall protein degradation by the ubiquitin proteasome system as well as by autophagy. Proc Natl Acad Sci U S A, 2015. 112(52): p. 15790-7.

156. Sharma, M., S. Rajendrarao, N. Shahani, U.N. Ramirez-Jarquin, and S. Subramaniam, Cyclic GMP-AMP synthase promotes the inflammatory and autophagy responses in Huntington disease. Proc Natl Acad Sci U S A, 2020. 117(27): p. 15989-15999. 
157. Sharma, M., U.N.R. Jarquin, O. Rivera, M. Kazantzis, M. Eshraghi, N. Shahani, V. Sharma, R. Tapia, and S. Subramaniam, Rhes, a striatal-enriched protein, promotes mitophagy via Nix. Proc Natl Acad Sci U S A, 2019. 116(47): p. 23760-23771.

158. Shahani, N., S. Swarnkar, V. Giovinazzo, J. Morgenweck, L.M. Bohn, C. ScharagerTapia, B. Pascal, P. Martinez-Acedo, K. Khare, and S. Subramaniam, RasGRP1 promotes amphetamine-induced motor behavior through a Rhes interaction network ("Rhesactome") in the striatum. Sci Signal, 2016. 9(454): p. ra111.

159. Eshraghi, M., U.N. Ramirez-Jarquin, N. Shahani, T. Nuzzo, A. De Rosa, S. Swarnkar, N. Galli, O. Rivera, G. Tsaprailis, C. Scharager-Tapia, G. Crynen, Q. Li, M.L. Thiolat, E. Bezard, A. Usiello, and S. Subramaniam, RasGRP1 is a causal factor in the development of l-DOPA-induced dyskinesia in Parkinson's disease. Sci Adv, 2020. 6(18): p. eaaz7001.

160. Ramirez-Jarquin, U.N., N. Shahani, W. Pryor, A. Usiello, and S. Subramaniam, The mammalian target of rapamycin (mTOR) kinase mediates haloperidol-induced cataleptic behavior. Transl Psychiatry, 2020. 10(1): p. 336.

161. Guyenet, S.J., S.A. Furrer, V.M. Damian, T.D. Baughan, A.R. La Spada, and G.A. Garden, A simple composite phenotype scoring system for evaluating mouse models of cerebellar ataxia. J Vis Exp, 2010(39). 


\section{Figure 1}

A

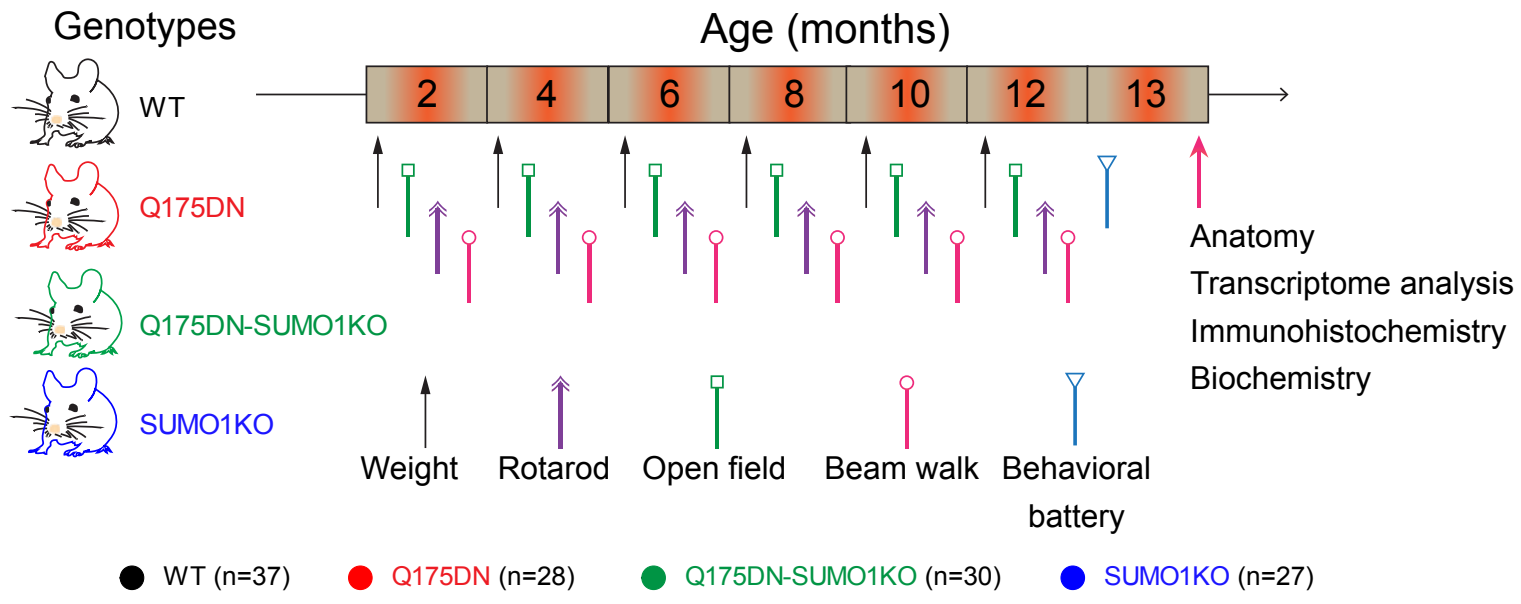

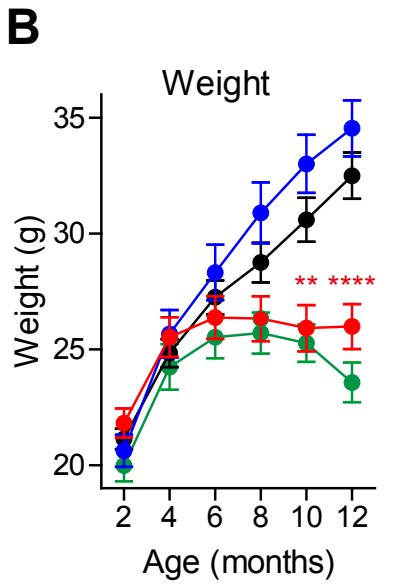

F

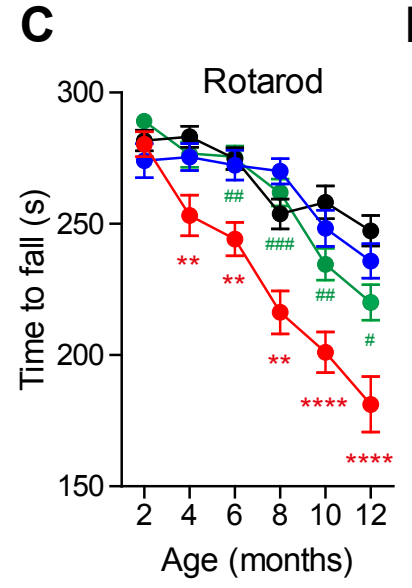

D

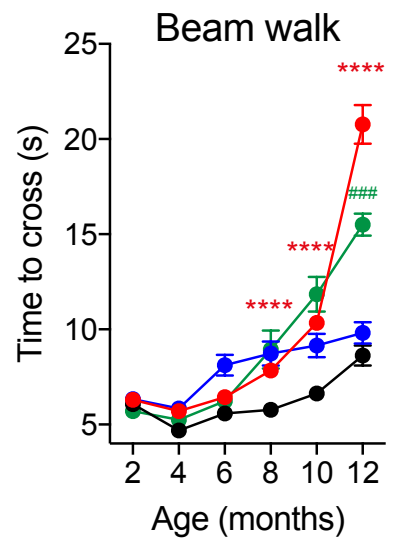

E

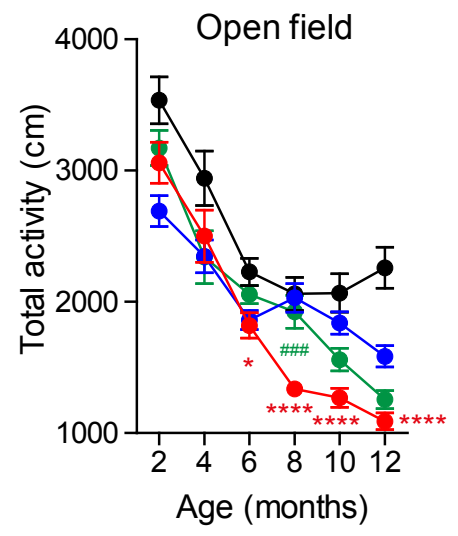

Behavioral battery

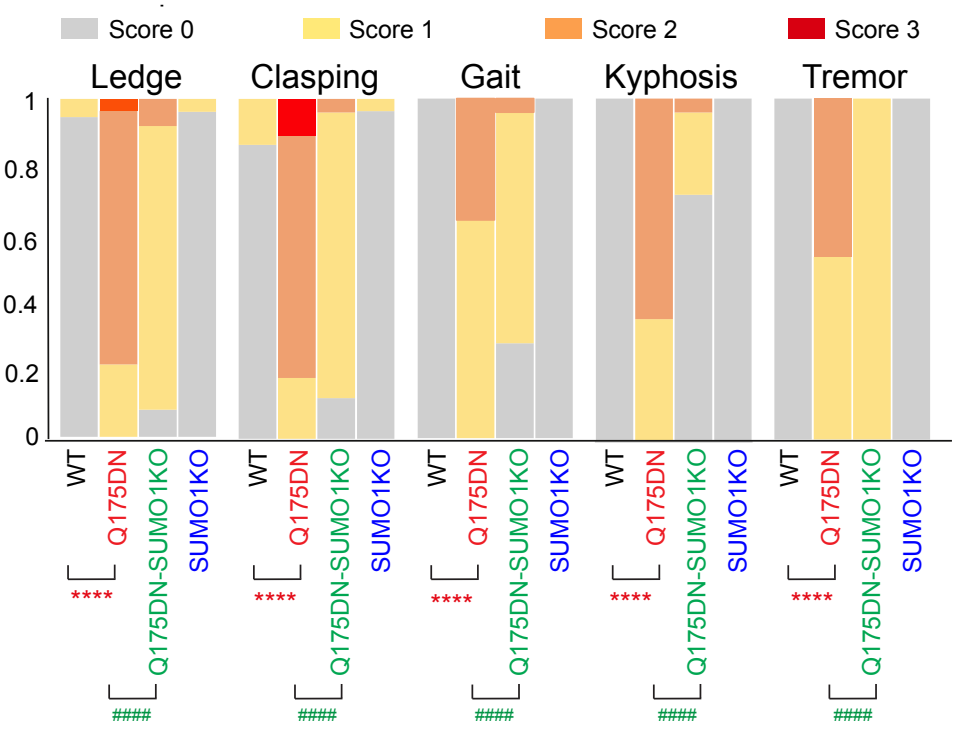

G

Behavioral battery

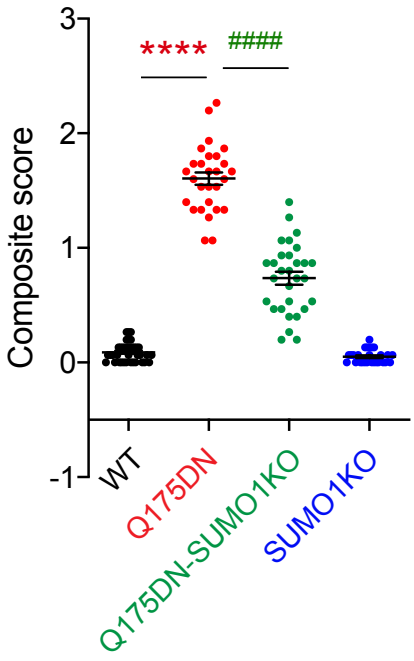


bioRxiv preprint doi: https://doi.org/10.1101/2021.02.15.431277; this version posted February 16, 2021. The copyright holder for this preprint (which was not certified by peer review) is the author/funder. All rights reserved. No reuse allowed without permission.

\section{Figure 2}

A

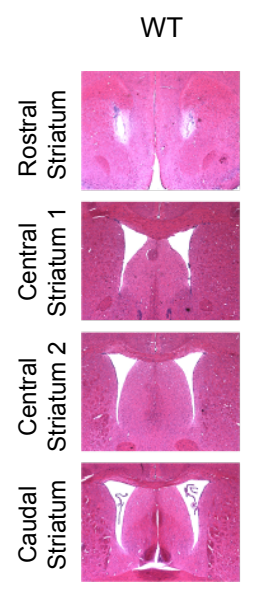

Q175DN
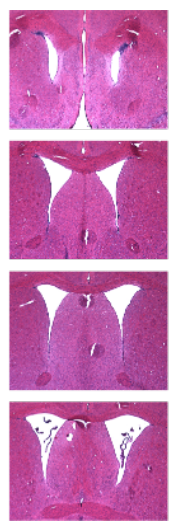

Q175DNSUMO1KO
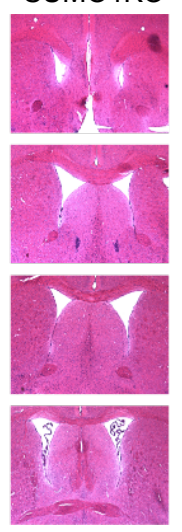

SUMO1KO

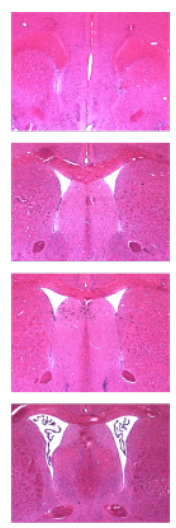

B

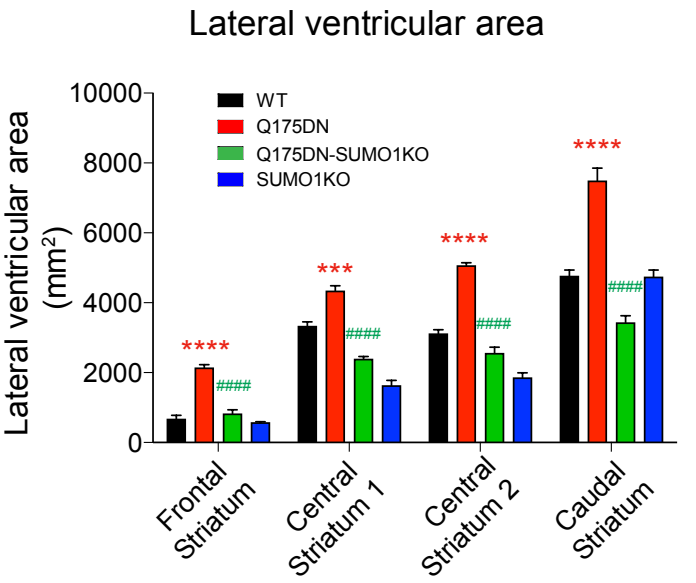

\section{C}

Q175DN vs WT

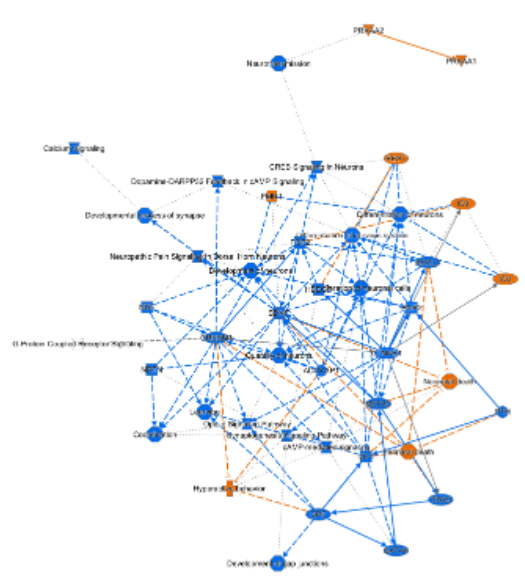

E

\begin{tabular}{|c|c|c|c|c|}
\hline Gene- & Name- & log2 FoldChange & padj & \\
\hline Gm28411 & Predicted gene & 7.799577458 & $1.85 E-06$ & \\
\hline Gm25813 & Predicted gene & 4.296830377 & 0.03413 & \\
\hline Aox4 & aldehyde oxidase 4 & 2.855935933 & 0.001854 & \\
\hline Hoxd8 & homeobox D8 & 2.61060363 & & \\
\hline Gm6089 & Predicted gene & 2.378378566 & 0.020149 & \\
\hline Gabra2 & Gamma-Aminobutyric Acid Type A Receptor Subunit & 1.389739129 & $3.26 \mathrm{E}-10$ & \\
\hline $\mathrm{Nr} 4 \mathrm{a} 3$ & Nuclear Receptor Subfamily 4 Group A Member 3 & 1.314265255 & $3.78 \mathrm{E}-08$ & \\
\hline IHist1h4n & $\mathrm{H} 4$ clustered histone 18 & 1.308202853 & 0.028771 & \\
\hline iWdfy 1 & WD Repeat And FYVE Domain Containing 1 & 1.271727335 & 0.000752 & \\
\hline Scarna2 & Small Cajal Body-Specific RNA 2 & 1.023278608 & 0.000445 & \\
\hline Gm38393 & Predicted gene & 0.634510204 & 0.020149 & \\
\hline & nicotinamide (NAD) nucleotide transhydrogenase & 0.595020463 & 0.000258 & \\
\hline & RNA imprinted and accumulated in nucles & 0.501827106 & 0.002515 & \\
\hline IZfip518a & zinc finger protein $518 \mathrm{~A}$ & -0.752146411 & 0.000535 & 5 down \\
\hline |Creb5 & CAMP responsive element binding protein 5 & -0.760627161 & 0.03246 & down \\
\hline Sp110 & SP110 Nuclear Body Protein & -5.980735122 & 0.008981 & down \\
\hline 0 & Predicted gene & -6.657144699 & $5.42 E-07$ & down \\
\hline & & & & \\
\hline
\end{tabular}

Q175DN vs WT

\begin{tabular}{|c|c|c|}
\hline Name & p-value & Overlap \\
\hline CREB Signaling in Neurons & $7.91 \mathrm{E}-21$ & $13.6 \% 81 / 597$ \\
\hline Opioid Signaling Pathway & $1.15 \mathrm{E}-20$ & $20.2 \% 50 / 247$ \\
\hline G-Protein Coupled Receptor Signaling & $1.04 \mathrm{E}-18$ & $18.3 \% 50 / 273$ \\
\hline $\begin{array}{l}\text { Endocannabinoid Neuronal Synapse } \\
\text { Pathway }\end{array}$ & $9.99 \mathrm{E}-15$ & $\% 30 / 128$ \\
\hline Glutamate Receptor Signaling & $6.83 E-14$ & $35.1 \% 20 / 57$ \\
\hline
\end{tabular}

$\mathbf{F}$

Q175DN-SUMO1KO vs Q175DN

\begin{tabular}{|c|c|c|}
\hline Name & $p$-value & Overlap \\
\hline $\begin{array}{l}\text { Hypoxia Signaling in the Cardiovascular } \\
\text { System }\end{array}$ & $6.76 \mathrm{E}-04$ & $2.7 \% 2 / 74$ \\
\hline Neuroinflammation Signaling Pathway & 1.05E-02 & $0.7 \% 2 / 300$ \\
\hline Circadian Rhythm Signaling & 1.73E-02 & $3.0 \% 1 / 33$ \\
\hline $\begin{array}{l}\text { DNA Methylation and Transcriptional } \\
\text { Repression Signaling }\end{array}$ & $1.83 \mathrm{E}-02$ & $2.9 \% 1 / 35$ \\
\hline $\begin{array}{l}\text { Role of IL-17F in Allergic Inflammatory } \\
\text { Airway Diseases }\end{array}$ & 2.20E-02 & $2.4 \% 1 / 42$ \\
\hline
\end{tabular}




\section{Figure 3}

A
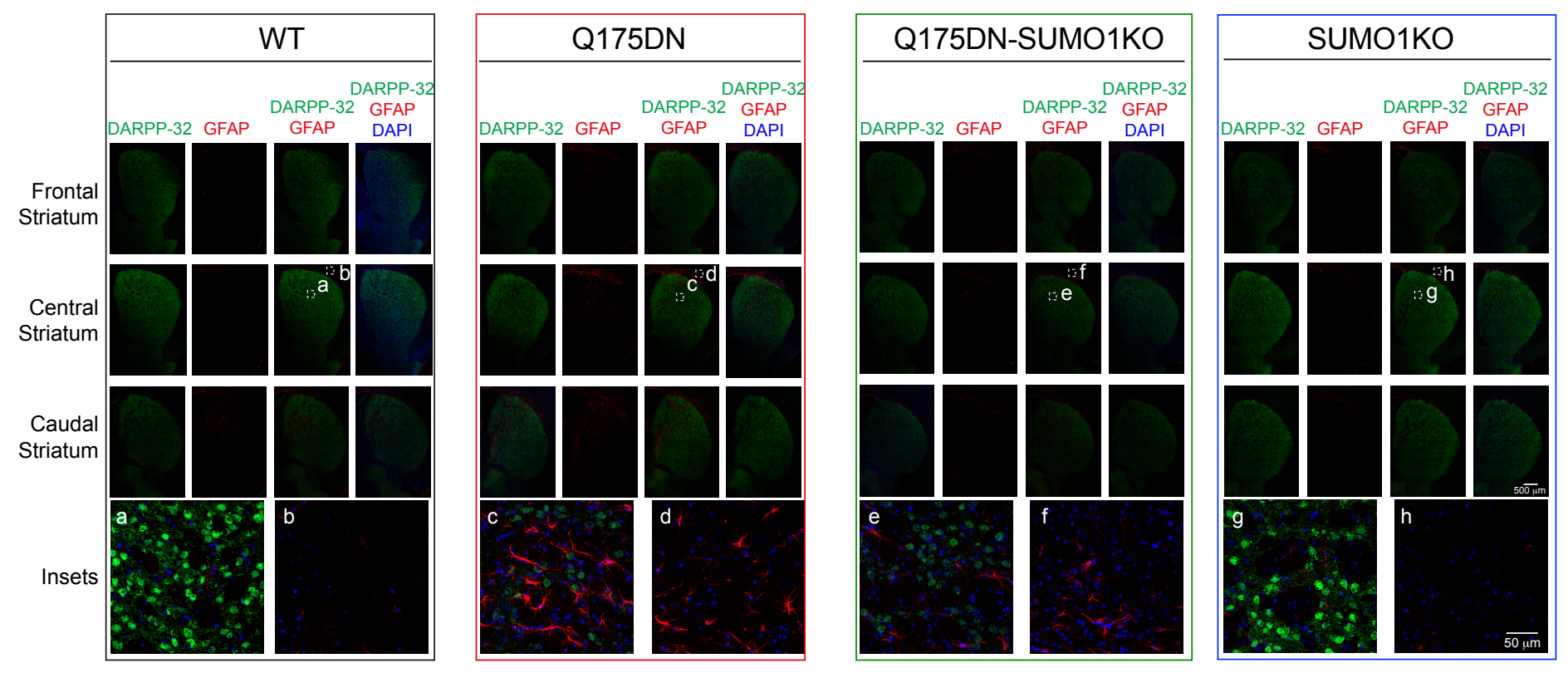

- WT • Q175DN • Q175DN-SUMO1KO • SUMO1KO
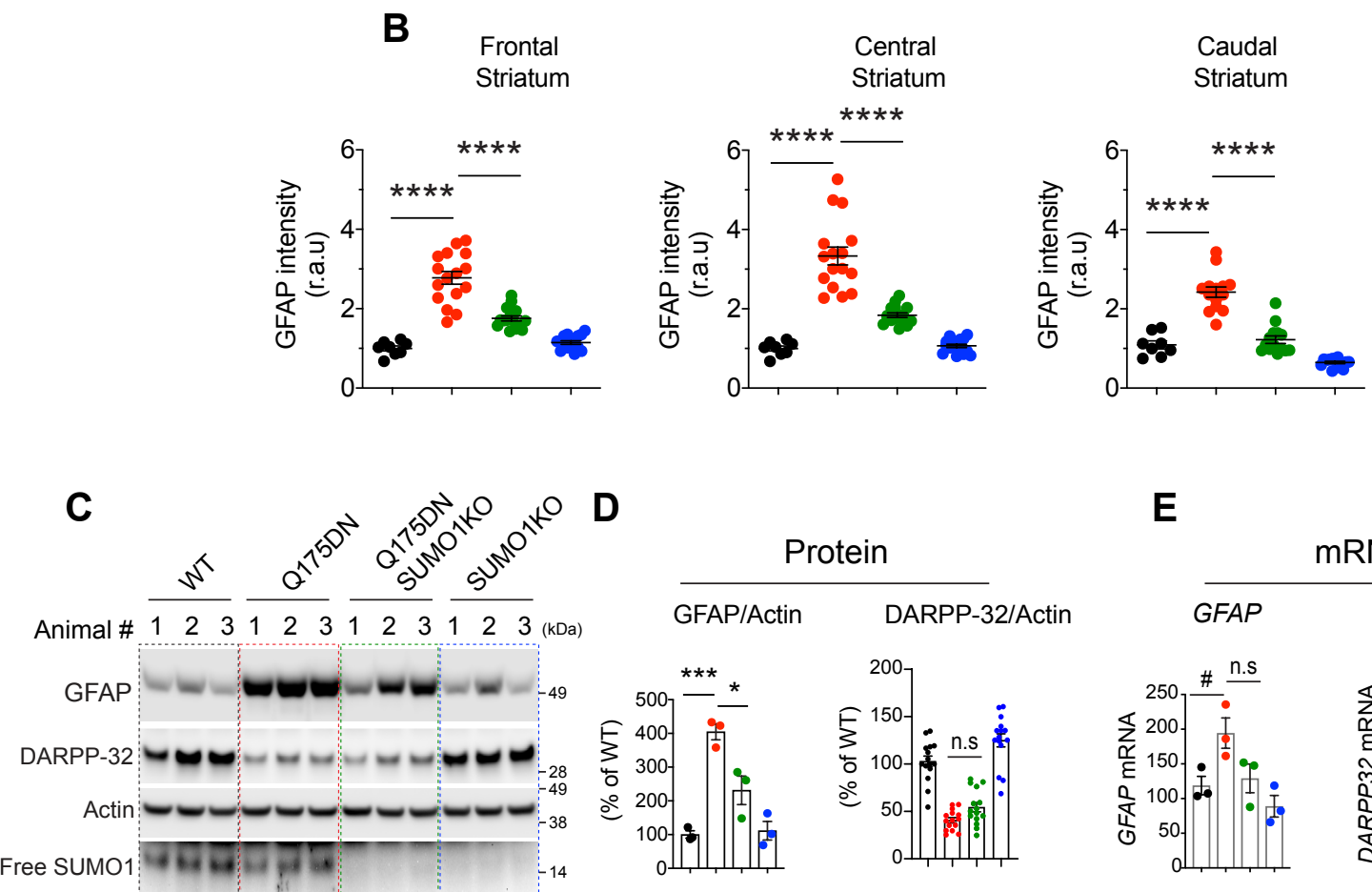

D
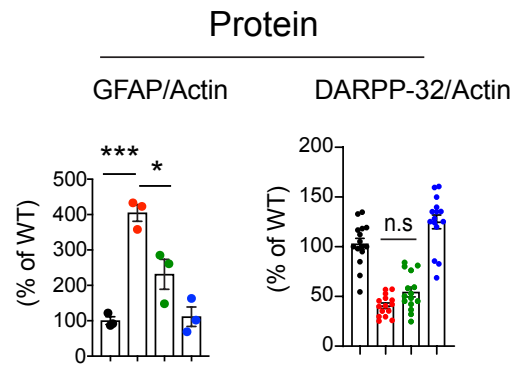

E

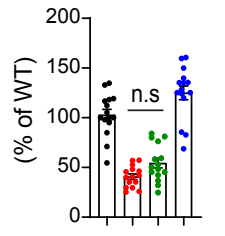

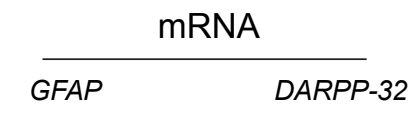
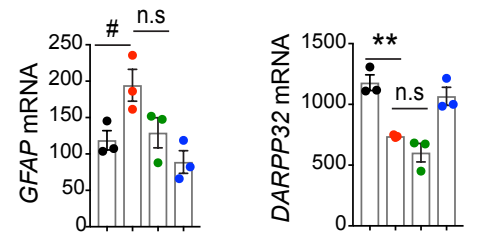


\section{Figure 4}

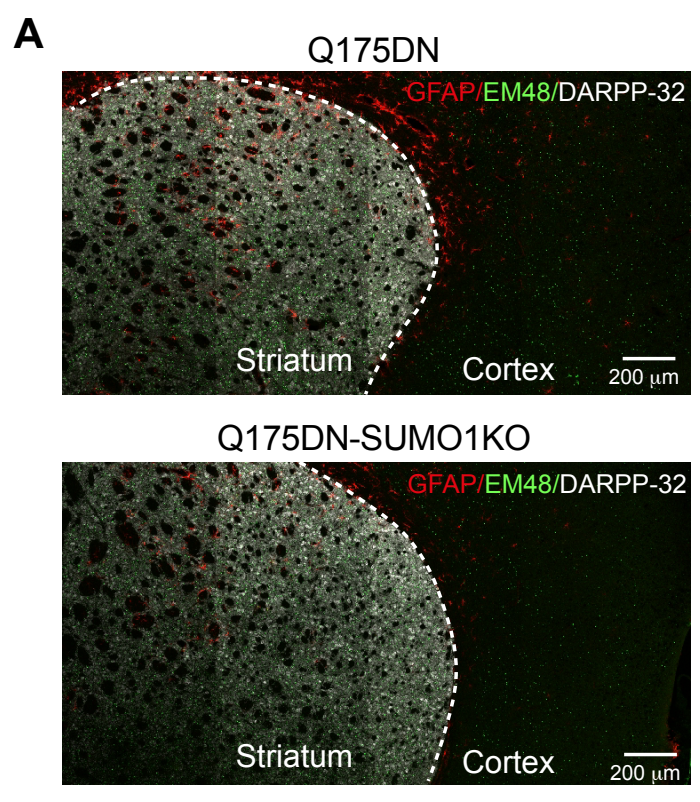

B

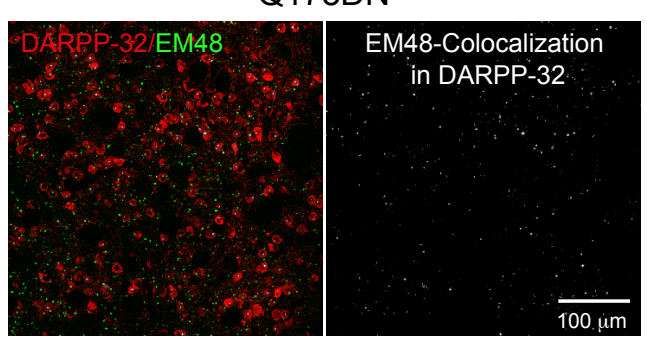

Q175DN-SUMO1KO
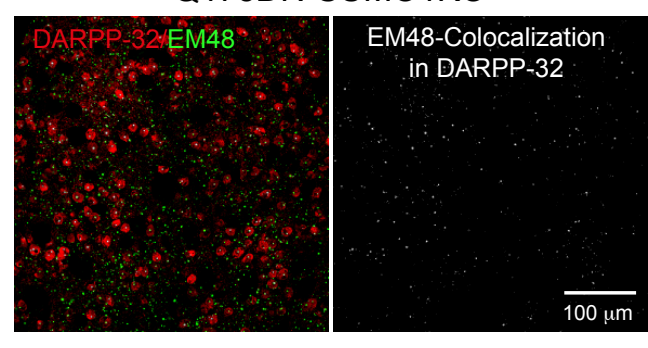

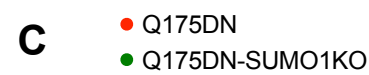

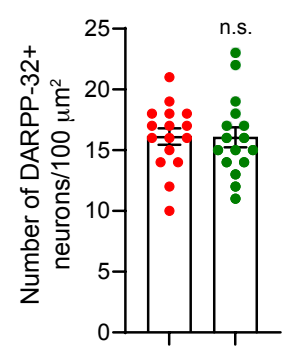

D

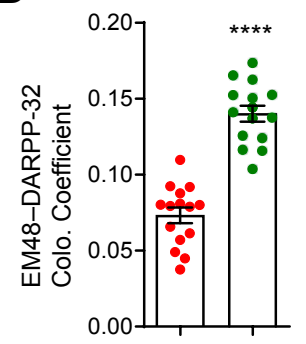

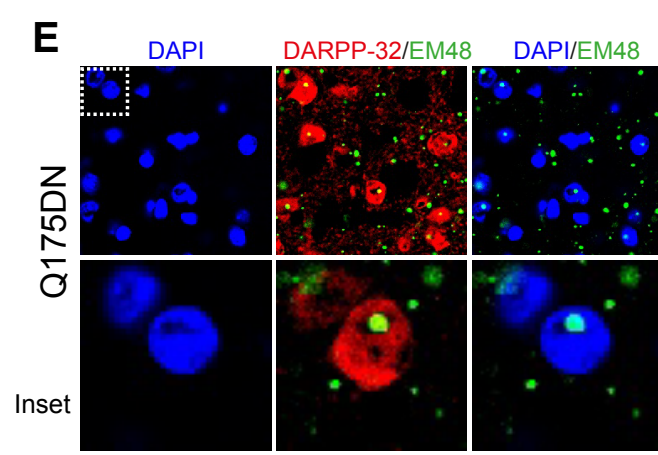

DAPI/DARPP-32
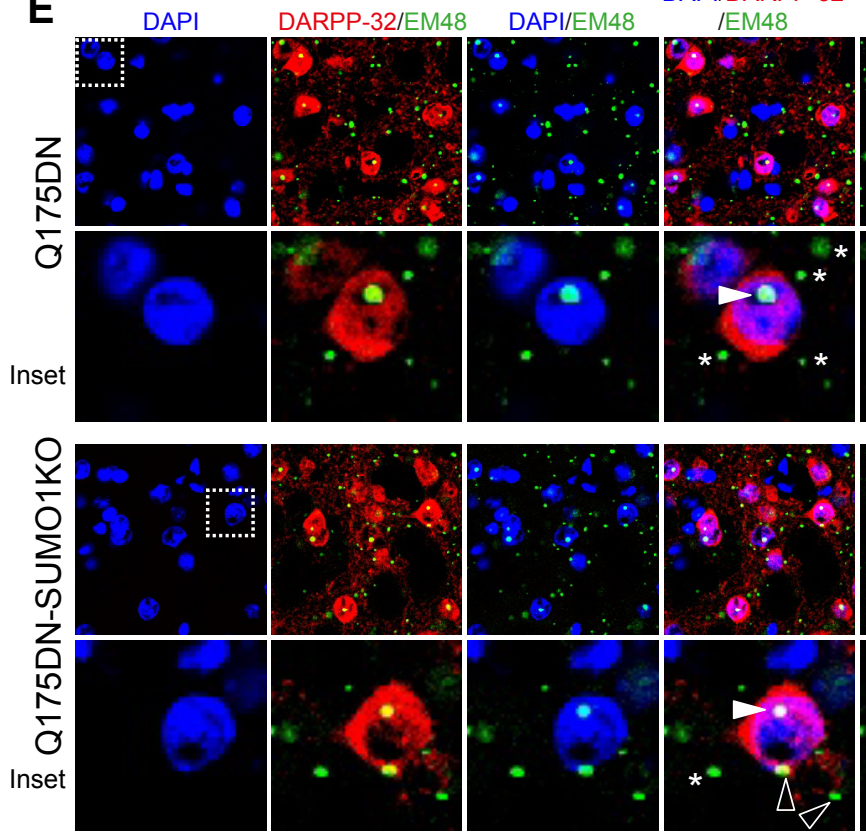

K

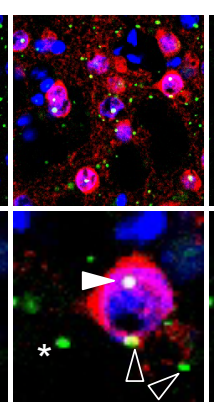

F
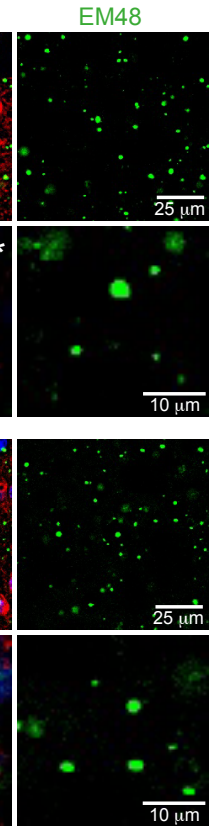
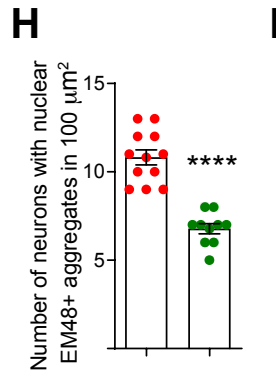

M
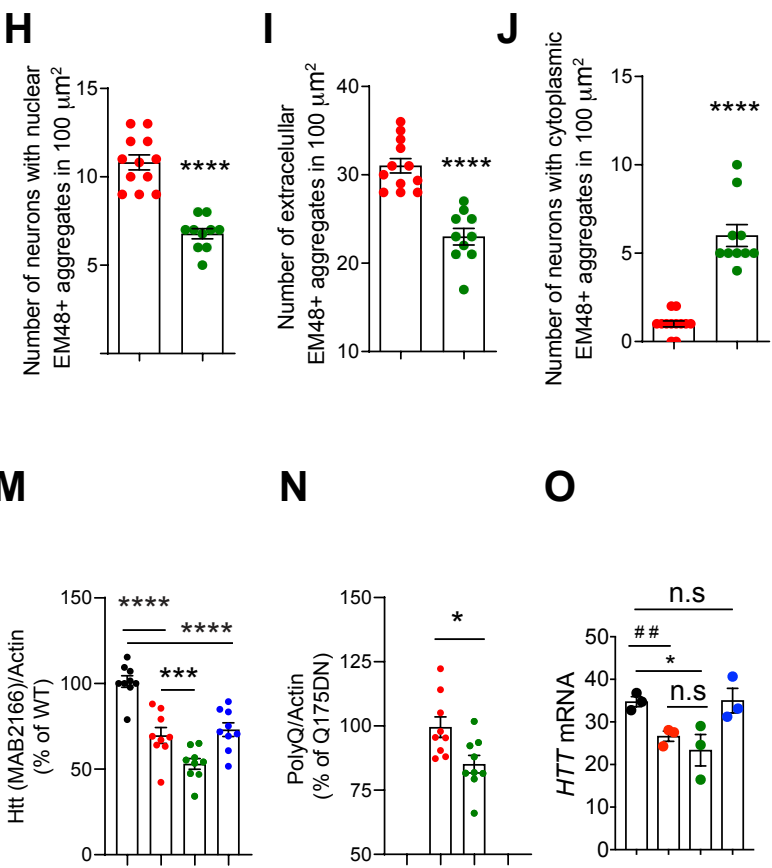

$\mathrm{Htt}(\mathrm{EM} 48)$
(high $\exp )$

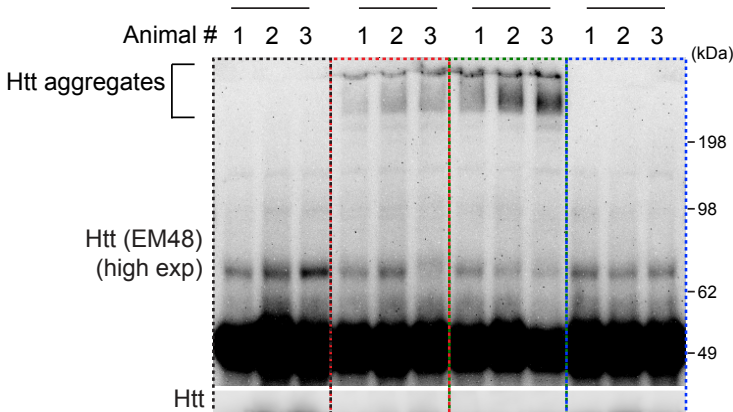

$\begin{array}{r:rl}\mathrm{Htt} & \mathbf{M A B 2 1 6 6 )} & -\end{array}$

- WT

- Q175DN

- Q175DN-SUMO1KO

- SUMO1KO 
Figure 5

A

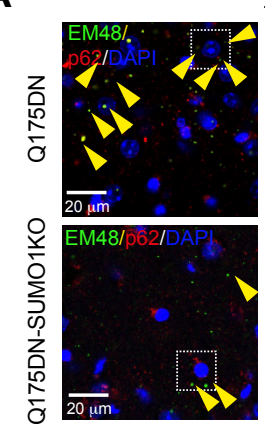

C

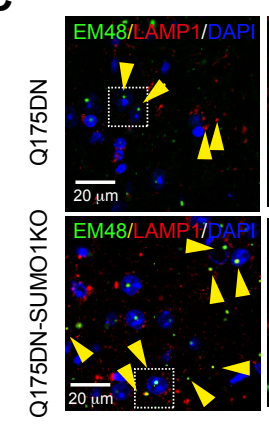

E

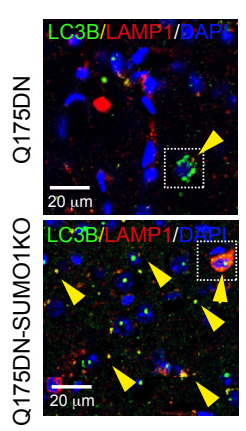

G

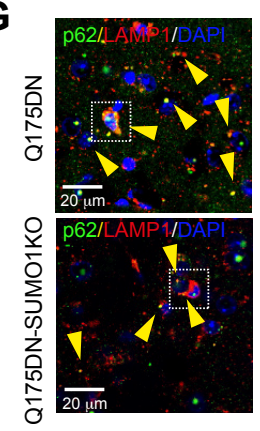

Inset
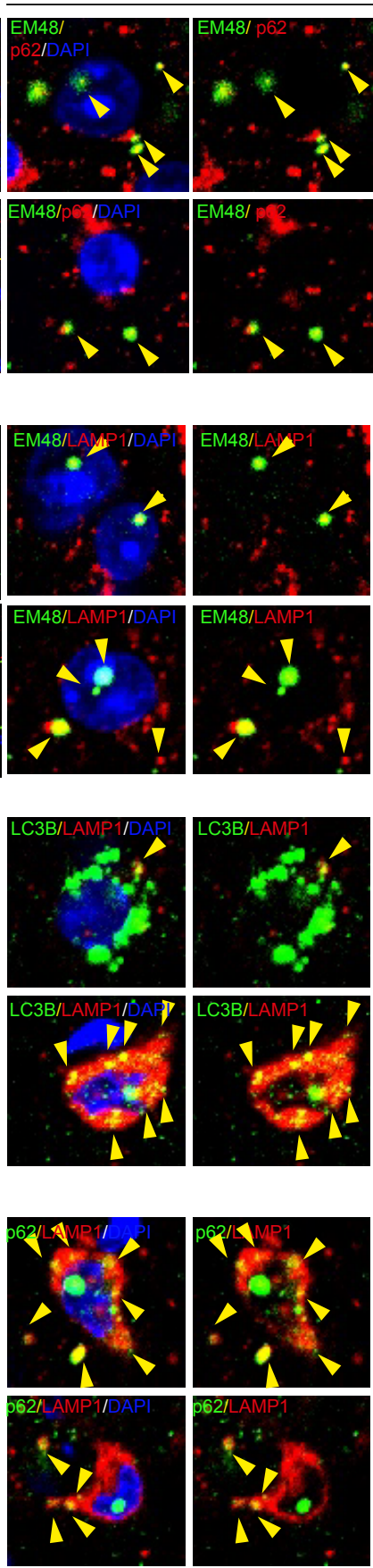
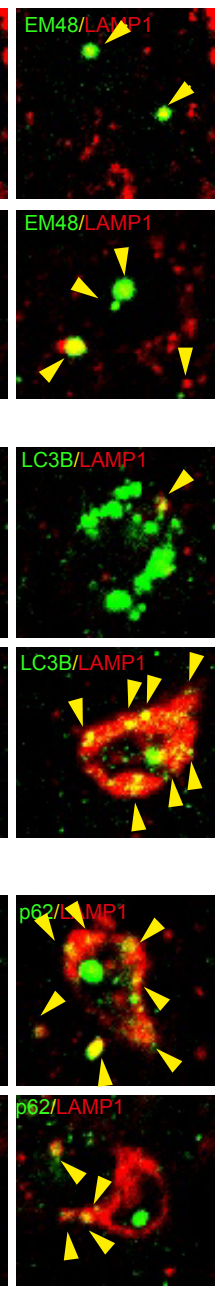
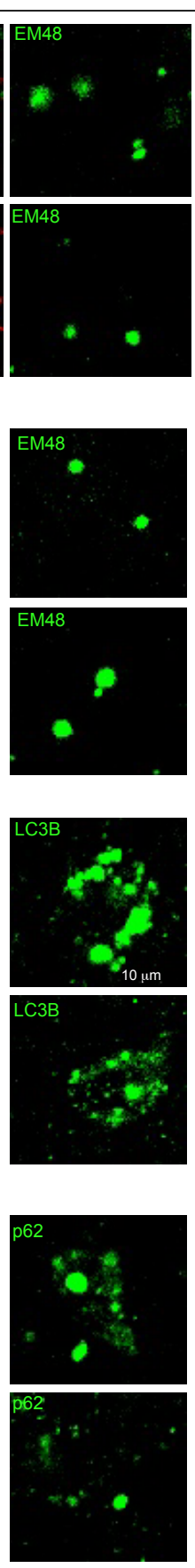

B
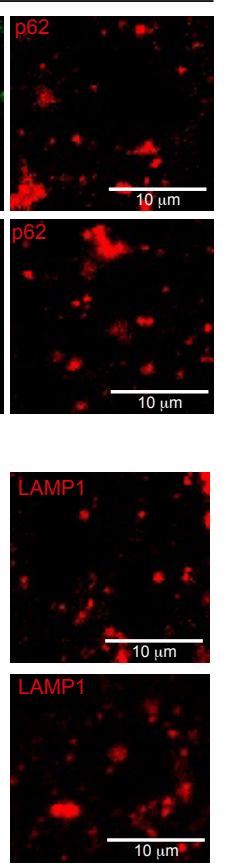

D

F

H

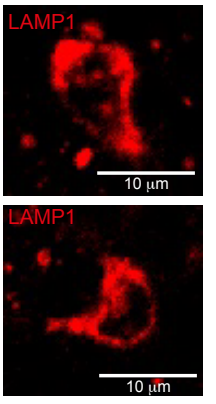

- Q175DN-SUMO1KO

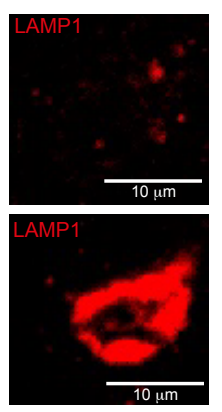

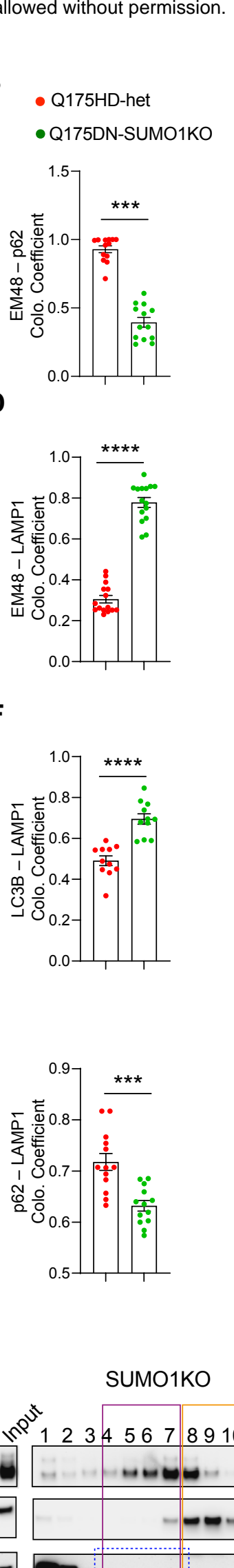
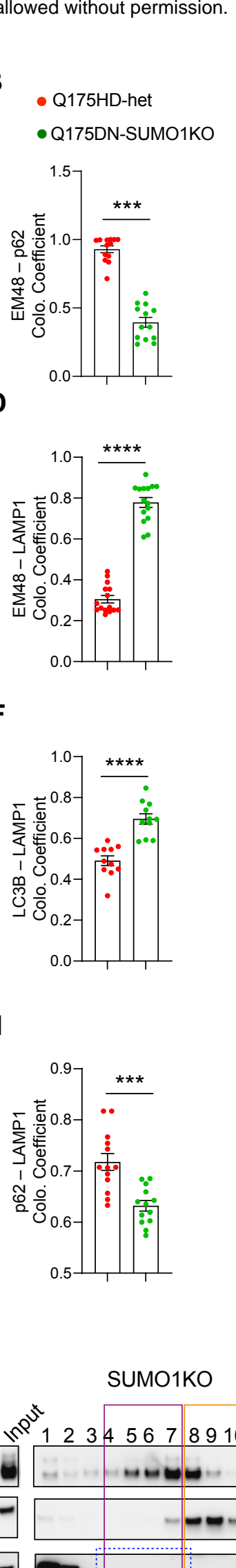

I

\section{fraction}

number

WT

Q175DN

Q175DN-SUMO1KO

SUMO1KO
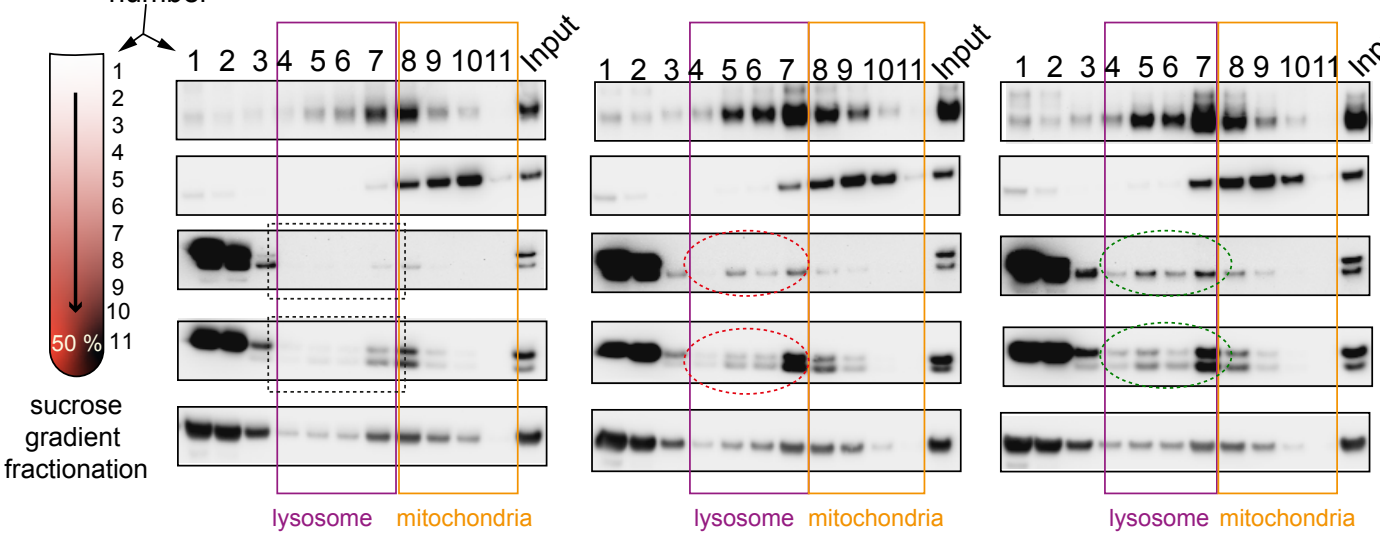

Q

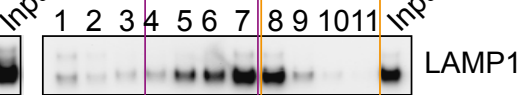

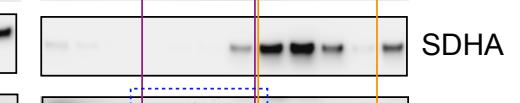

$=$
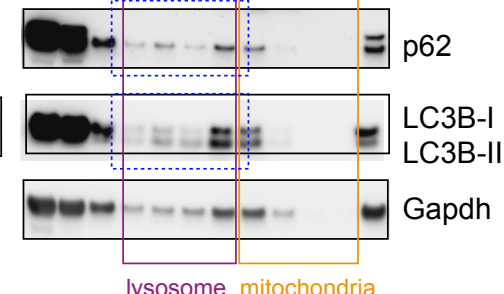
bioRxiv preprint doi: https://doi.org/10.1101/2021.02.15.431277; this version posted February 16, 2021. The copyright holder for this preprint Figure 6 (which was not certified by peer review) is the author/funder. All rights reserved. No reuse allowed without permission.

A $\quad$ B

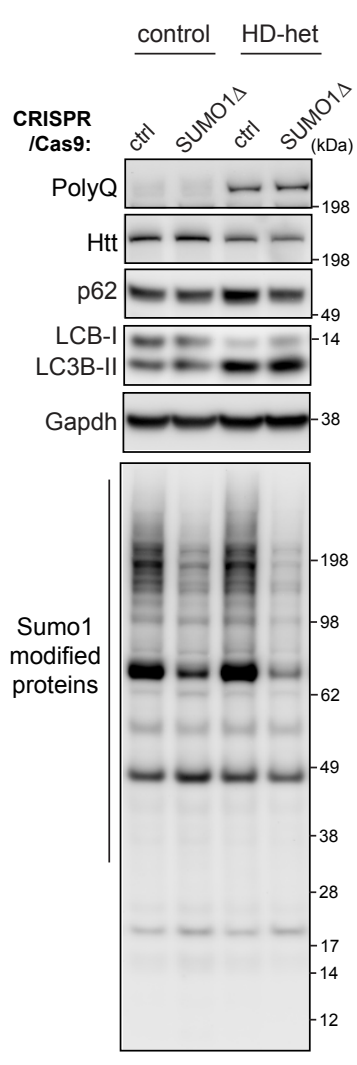

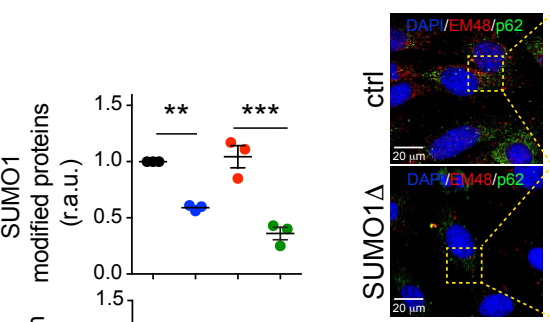

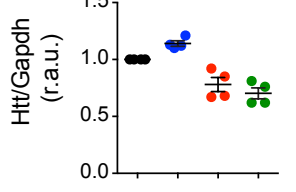

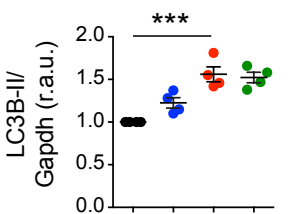

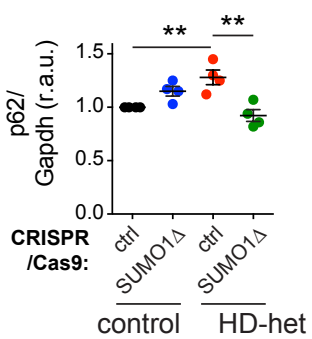

E

C

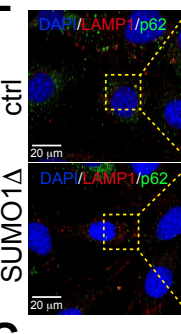

G

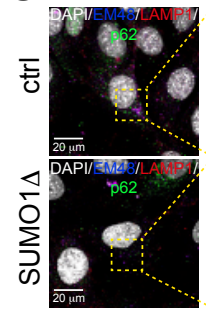

HD-het

Inset
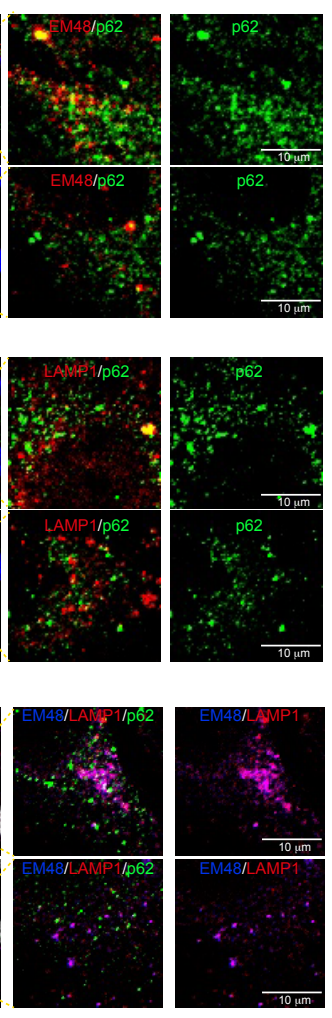

D
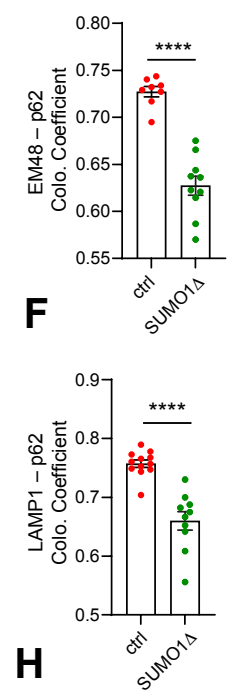

\section{H}

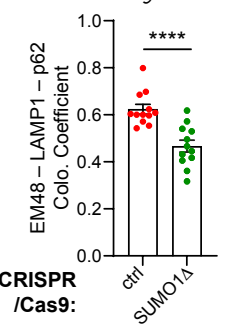

control

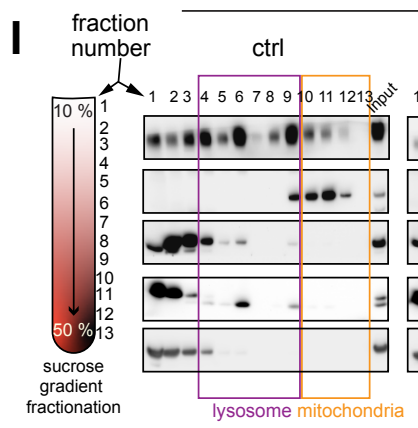

SUMO1A

450780
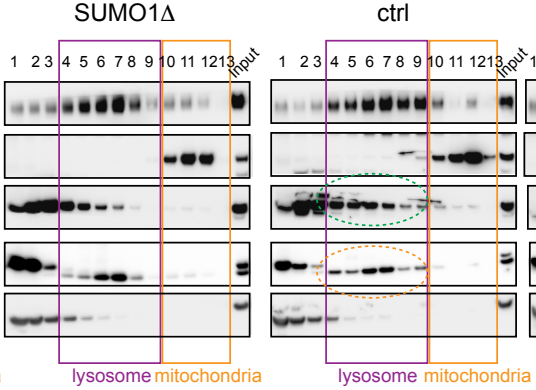

HD-het

SUMO1A

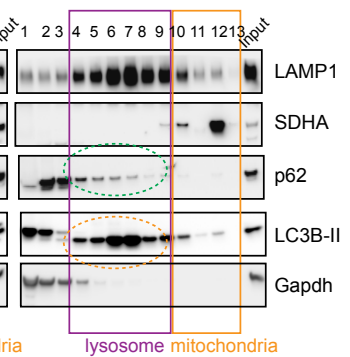

HD-het$$
\text { J }
$$

fraction ctrl

ctrl SUMO1

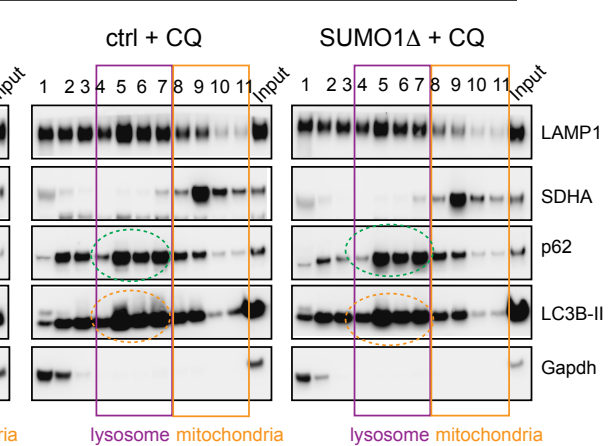

SUMO1 $1 \Delta+C Q$
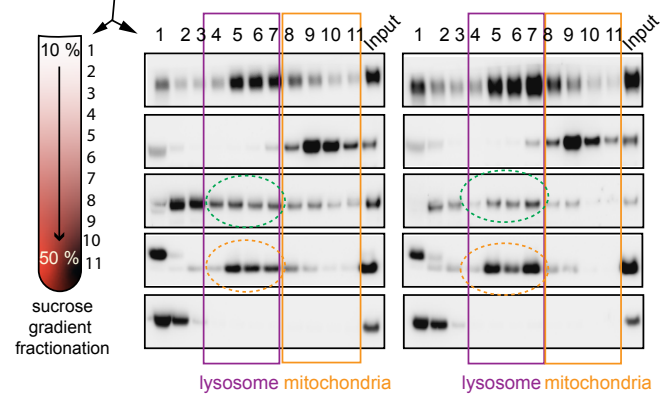
bioRxiv preprint doi: https://doi.org/10.1101/2021.02.15.431277; this version posted February 16,2021 . The copyright holder for this preprint

A Striatal cells
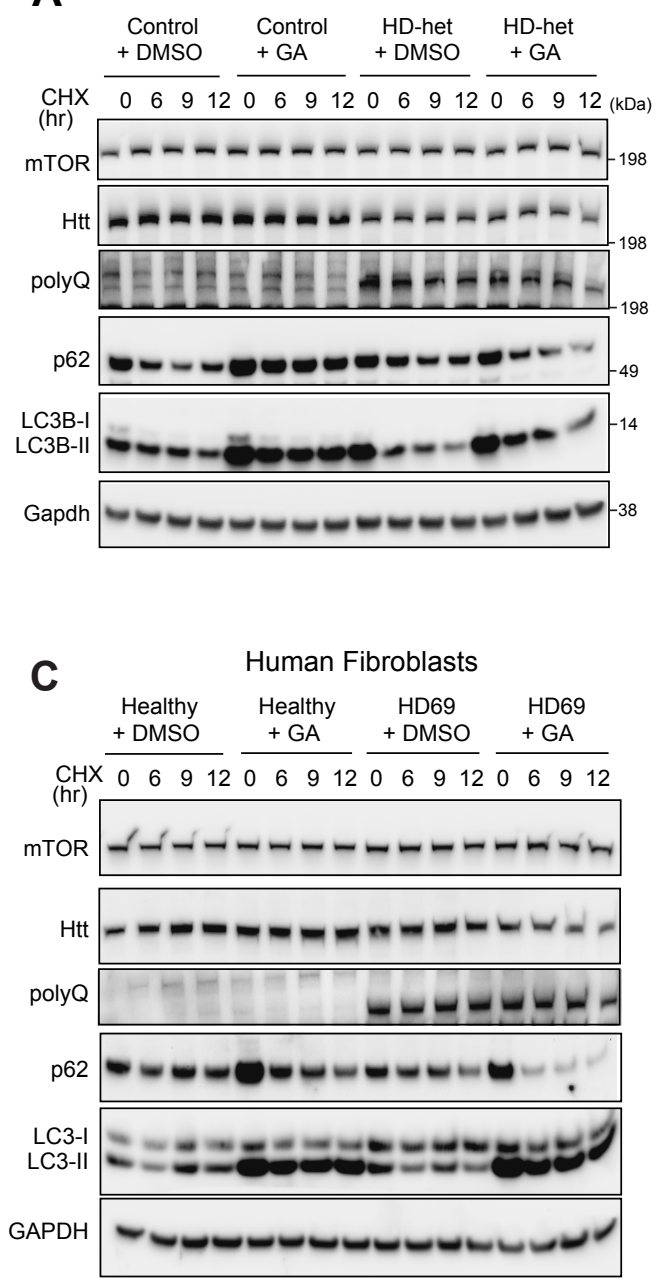

E

Huntington disease
SUMO-intact

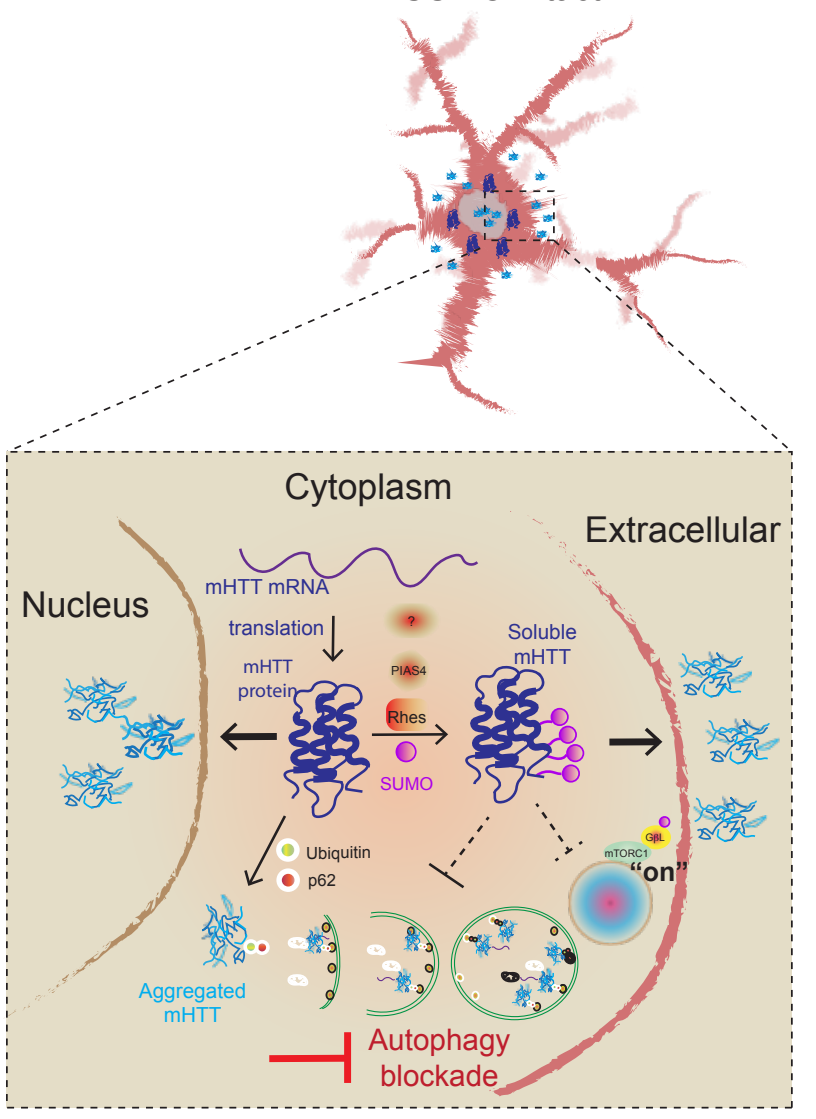

B
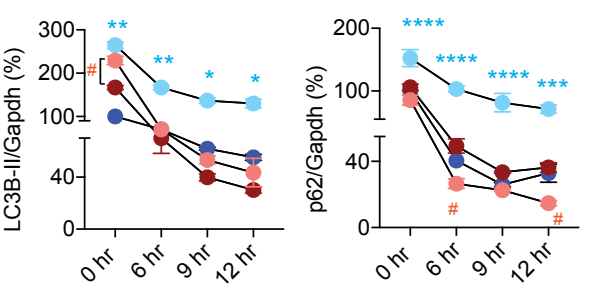

- Control+ DMSO

- Control + GA

- HD-het + DMSO

- HD-het + GA
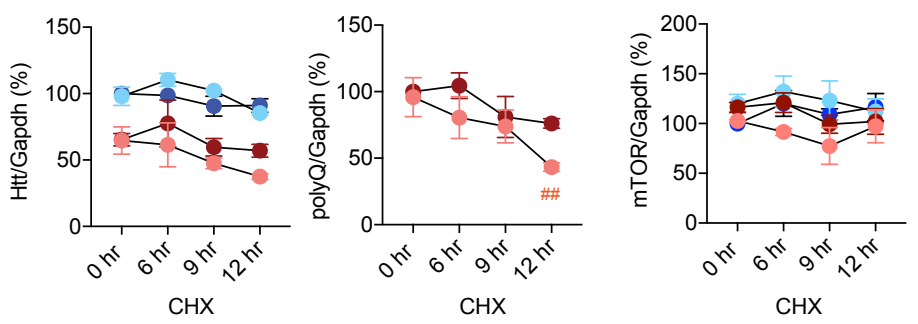

D
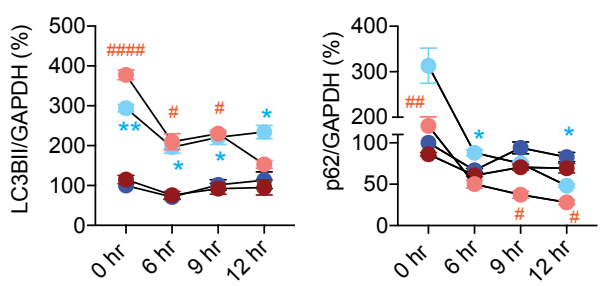

- Healthy + DMSO

- Healthy + GA

- HD69 + DMSO

- HD69+GA
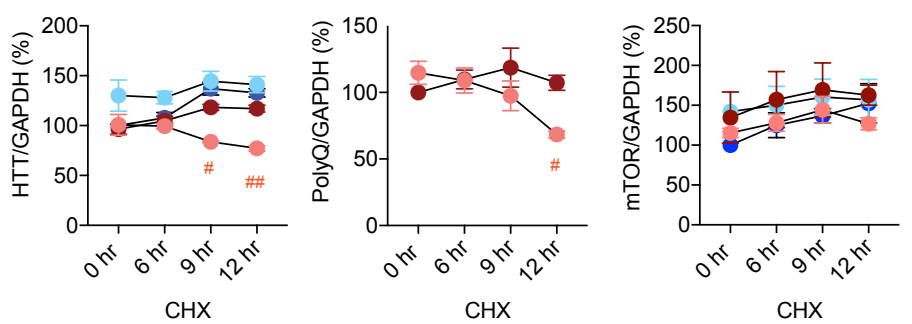

$\mathrm{CHX}$

Huntington disease SUMO-depleted

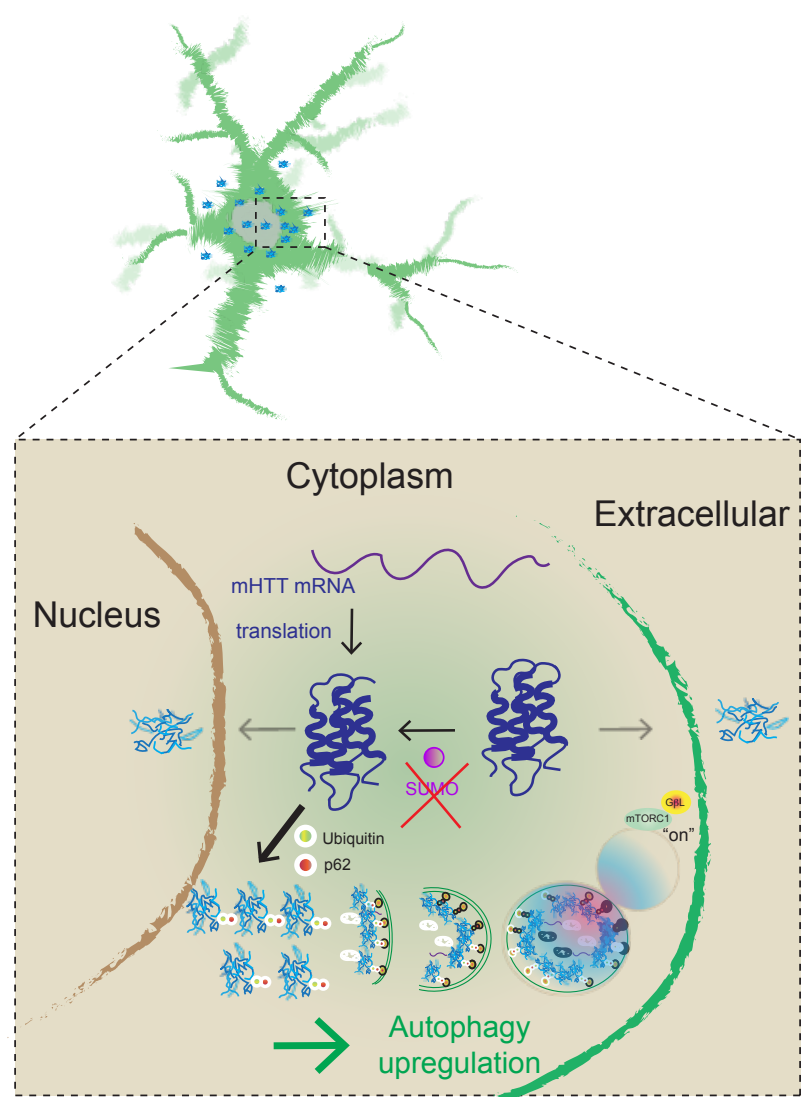


A Q175HD_VS_SUMOKO

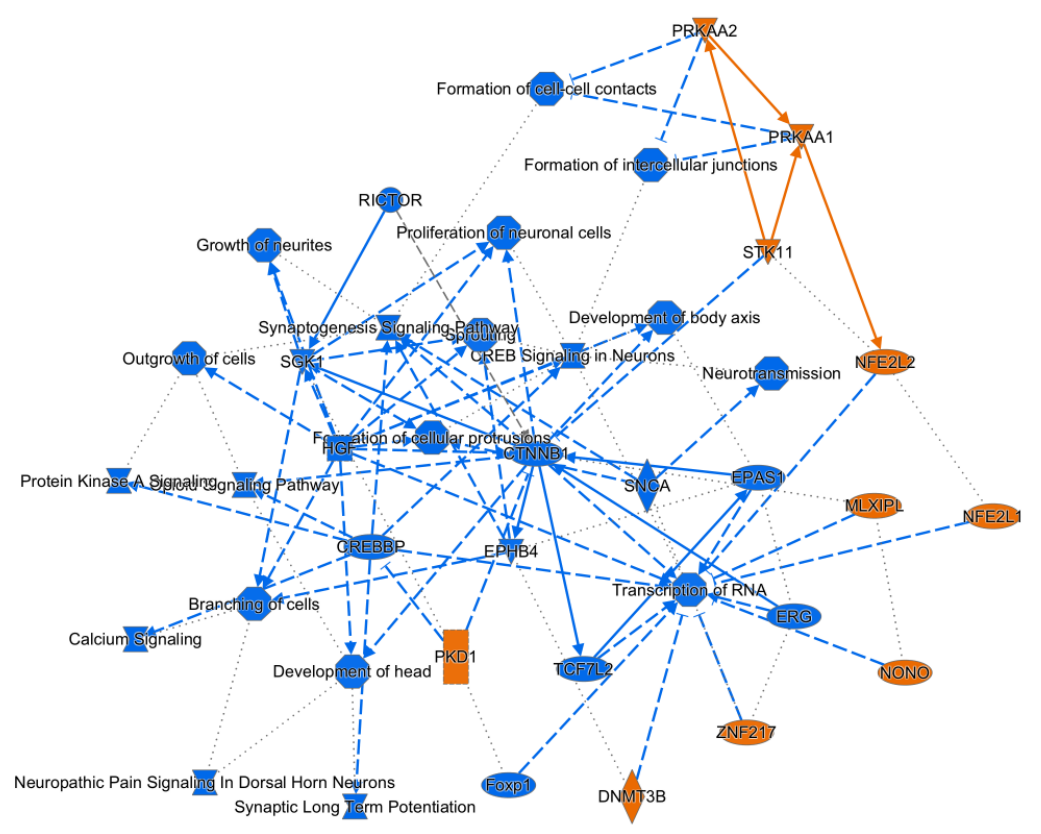

$\begin{array}{lcccc}\text { Name } & \text { p-value } & & \text { Overlap } \\ \text { Opioid Signaling Pathway } & 1.51 \mathrm{E}-10 & & 20.6 \% 51 / 247 \\ \text { Synaptogenesis Signaling Pathway } & 4.75 \mathrm{E}-09 & & 17.9 \% 56 / 312 \\ \text { Neuropathic Pain Signaling In Dorsal Horn } & 1.09 \mathrm{E}-08 & & 26.7 \% 27 / 101 \\ \text { Neurons } & & & & \\ \text { G-Protein Coupled Receptor Signaling } & & 4.28 \mathrm{E}-08 & & 17.9 \% 49 / 273 \\ \text { Synaptic Long Term Depression } & 6.72 \mathrm{E}-08 & & 20.1 \% 38 / 189\end{array}$

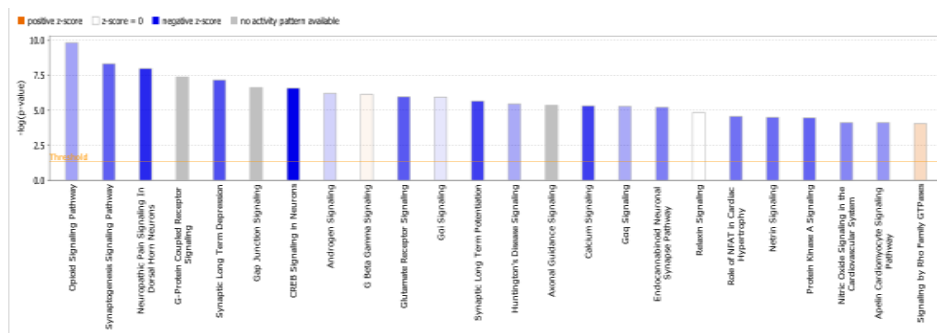

B

\section{WT_VS_SUMO KO}

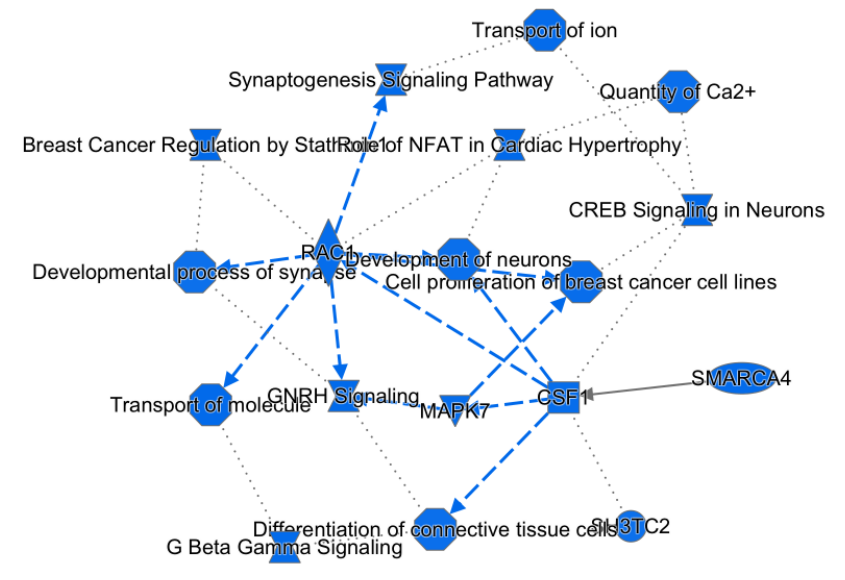

Name

CREB Signaling in Neurons

GPCR-Mediated Nutrient Sensing in Enteroendocrine Cells

G Beta Gamma Signaling GNRH Signaling

Synaptogenesis Signaling Pathway $\mathrm{p}$-value

2.06E-08

1.41E-07

3.15E-07

1.04E-06

2.34E-06
Overlap

$3.9 \% 23 / 597$

$8.9 \% 10 / 112$

$8.2 \% \quad 10 / 122$

$6.4 \% \quad 11 / 173$

$4.5 \% 14 / 312$

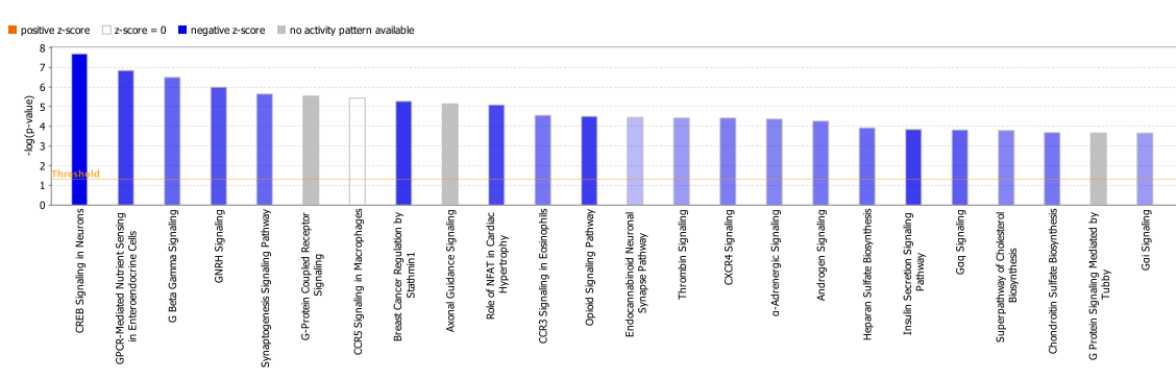

Supplementary figure冈 